\title{
A Fourth Contribution to our Knowledge of the Anatomy of the Cone and Fertile Stem of Equisetum.
}

\author{
BY \\ ISABEL M. P. BROWNE. \\ With Plate XXI and twelve Figures in the Text. \\ I. MATERIAL.
}

$\mathrm{T}$ the course of the present investigations the cones of three species, IE. sylvaticum, L., E. debile, Roxb., and E. variegatum, Schleich, were studied. Of $E$. sylvaticum three cones, $\mathrm{A}, \mathrm{B}$, and $\mathrm{C}$, were cut serially into transverse sections. In the cases of Cones $\mathrm{A}$ and $\mathrm{B}$, the sections extended to a level just below the annulus, but in Cone $\mathrm{C}$ the series ended just below the insertion of the lowest whorl of sporangiophores. A fourth cone, D, was cut serially into longitudinal sections.

Five cones of $E$. debile, henceforward referred to as Cones A, B, C, D, and $\mathrm{E}$, were cut serially into transverse sections, and a sixth cone, $\mathrm{F}$, was cut into serial longitudinal sections. Below Cones A, B, and $\mathrm{C}$ the series of sections was continued so as to include the uppermost node of the cone-bearing branch, while below Cone $\mathrm{E}$ the series of sections extended to a point just below the second node in a downward direction.

Of $E$. variegatum serial transverse sections were obtained of three cones, A, B, and C. Below Cone A the series of sections was prolonged, so as to include two vegetative nodes. Of a fourth cone, $D$, serial transverse sections were made of the region transitional from annulus to cone.

The following table gives particulars as to the size and constitution of the cones. In all cases, except in that of Cone $\mathrm{C}$ of $E$. sylvaticum, the

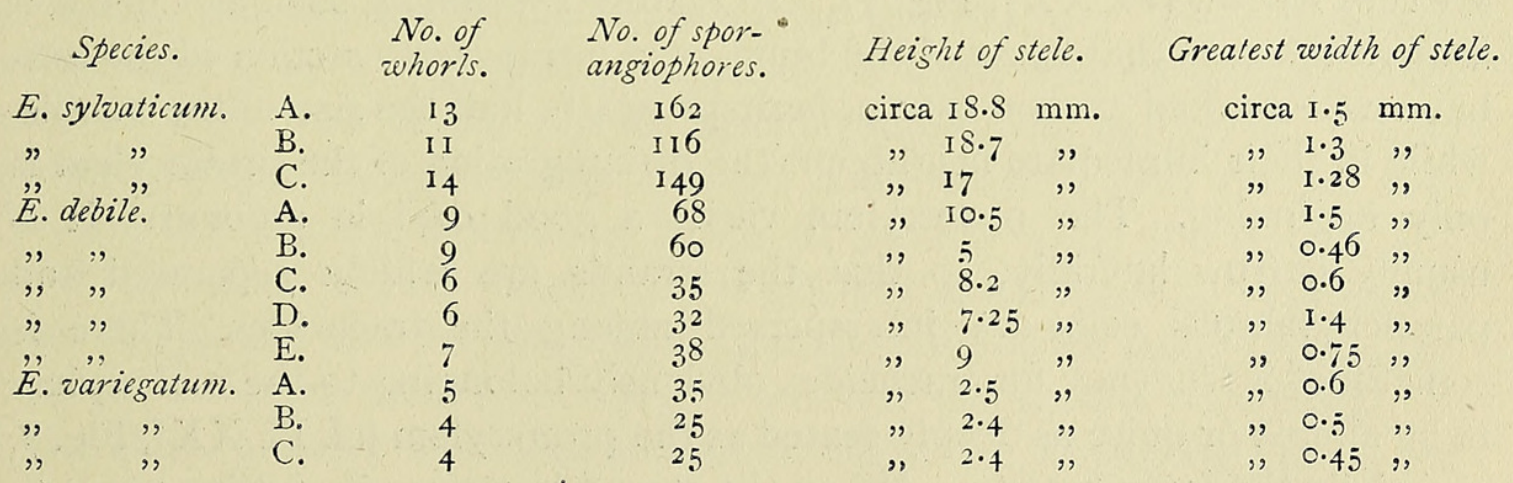

[Annals of Botany, Vol. XXXV. No. CXXXIX. July, I921.] 


\section{Browne. - A Fourth Contribution to our Knowledge of}

height of the stele was measured from a point just below the insertion of the annulus to the level, above the last whorl of sporangiophores, at which the vascular structure characteristic of the extreme apex of the cone is established.

\section{General Description.}

The cone of $E$. sylvaticum more closely resembles in its anatomy the cones of $E$. arvense and $E$. maximum than those of the other species studied. The resemblance is closest to the cone of $E$. maximum. The radial extent of the axial xylem is slight : except in the neighbourhood of the rather more deeply seated groups of protoxylem, the metaxylem is usually only one to two (often only one) cells in depth. Moreover, a few parenchymatous cells are not uncommonly interspersed in the tracheides of the metaxylem, though in the species under consideration this intercalation of parenchyma among the tracheides is not as extensive as in $E$. maximum. Nevertheless, in a transverse section of the cone of $E$. sylvaticum, the general resemblance to the cone of $E$. maximum is striking, especially, of course, to the smaller specimens of the latter species. The wide stele, the relatively numerous strands, the small radial extent of the metaxylem, its interruption by parenchyma, the small size of the traces, the presence and distribution of the tannin cells, all these characters in combination vividly recall the cone of $E$. maximum. But, relatively to its size, the cone of $E$. sylvaticum has a better developed vascular system. For instance, in the cone of the latter species the protoxylem generally abuts throughout most of its course on the metaxylem, whereas in E. maximum a few parenchymatous cells intervene in the internode of the cone between protoxylem and metaxylem (cf. Barratt, p. 224, Text-fig. 2 I).

Though typical endodermal markings are not well shown in the axis of the cone a common outer endodermis can be distinguished, comparable to that of the ordinary stems. There was no trace of a common inner endodermis, such as Pfitzer found in the rhizome (Pfitzer, pp. $3^{1} 3^{-14}$ ).

The tracheides of the cone of $E$. debile are of the usual type. Though bands of xylem occur locally (cf. Text-figs. 3-6) many of the strands are very narrow (Pl. XXI, Fig. 7). In mature specimens, such as Cone A, it is often the case that some of the bundles in a transverse section of the axis have well-marked carinal canals, perhaps nearly half the size of the bundle. while in their immediate neighbours the disintegration of the protoxylem is only beginning. The metaxylem varies a good deal in amount. It is usually narrow laterally, so that the strands are widely separated and parenchymatous cells are interspersed among the tracheides. There is sometimes a tendency for tracheides obviously belonging to the metaxylem to be almost or quite as deeply seated as the protoxylem (cf. Pl. XXI, Fig. 7, especially the large bundle). When the strand is narrow its outline tends to 
be more or less circular or even oval with the slightly longer axis directed radially. But, though the radial extent of the xylem is often considerable, compared with its width, the actual number of tracheides in the metaxylem of the small bundle is not great and a comparison with the bundles in younger, immature cones shows that the disorganized protoxylem elements, replaced by relatively large carinal canals, were few in number. Protoxylem and metaxylem are usually continuous, but may be locally separated by parenchymatous cells.

The individual strands of the axis of the cone are closely surrounded by a sheath, often very distinct, the cells of which do not show typical endodermal markings. They are much larger than the cells of the bundle and are often radially elongated with reference to the latter (cf. Pl. XXI, Fig. 7). The sheath always follows closely the shape of the bundle, and when there is a band of xylem, formed by the coalescence of several strands, the cells of the sheath disappear at the points of junction of the strands, their place being taken by tracheides mixed with small parenchymatous cells. Thus the laterally elongated bands of vascular tissue are surrounded by sheaths exactly resembling those round the narrower bundles.

In the cone of $E$. variegatum the xylem also consists of tracheides of the usual type. The protoxylem is usually in contact with the metaxylem, and though parenchymatous cells are mingled with the tracheides they are not, as a rule, as numerous, even relatively to the size of the bundle, as in E. sylvaticum or E. maximum. The tracheides of metaxylem and protoxylem are often very similar; the latter may be irregularly scattered along the inner edge of the former and not distributed in definite groups. The amount and distribution of the metaxylem varies much, even in neighbouring bundles of a section. Perhaps the commonest form of strand is that in which the xylem forms an oval band, as seen in a transverse section of the axis, wider than deep, broken up by a few parenchymatous cells, but often attaining locally a depth of three to four cells, excluding the protoxylem (cf. Pl. XXI, Fig. 5).

Sometimes certain relatively large tracheides at the edge of the bundle appear to be more deeply seated than the protoxylem (Pl. XXI, Fig. 5, the bundle near the top of the figure on the reader's left). Such xylem is, ontogenetically speaking, centripetal, since its differentiation as tracheides occurred after that of the smaller celled protoxylem outside it. These relatively large tracheides abut on the large cells of the sheaths that surround the separate bundles or bands of vascular tissue and usually line one of the sides of this sheath. It is obvious from the early appearance round the bundle of a definite sheath that the cells of the latter soon attain too great a size for them to develop as ordinary metaxylem tracheides. It is, therefore, possible that when the conditions in the developing bundle are favourable to a considerable differentiation of metaxylem, the extension of 
the latter outwards or laterally being hindered by the large size already attained by the cells of the sheath, the direction of lignification of any further tracheides might be bound to follow more or less the outline of the sheath inwards. ${ }^{1}$ The disposition of these more deeply seated, large tracheides and their appearance, as we pass upwards, in continuity with the ordinary centrifugal metaxylem strongly suggest such an explanation. ${ }^{2}$ But though this is the general impression left by their appearance and position, it is of course possible that these elements are the remains of ancestral centripetal xylem.

Pfitzer (pp. $3^{10-1 I}, 3^{1} 3$ ) states that there are common inner and outer endodermes both in the stem and the rhizome of $E$. variegatum. In the cone, however, the separate bundles are surrounded by special, very distinct endodermes. When two bundles fuse, or when a strand increases in width, when it narrows or branches, the endodermis takes the outline of the vascular tissue (cf. Pl. XXI, Figs. 4, 5, and 8). Consequently the distribution of the endodermal cells is always varying, and they cannot be held to possess any morphological or phylogenetic importance.

\section{The Course of the Strands in the Cone.}

The network of strands in the cone of E. sylvaticum recalls that of the cones of $E$. maximum, especially of the smaller specimens with their relatively better developed vascular system. The reconstructions of the steles of Cones A and B of E. sylvaticum (Text-figs. I and 2) are very similar to the reconstruction of the stele of Cone A of E. maximum (cf. Browne (2), Pl. XII), allowance being made for the different scales of the figures and for the larger size and more numerous component parts of the cone in E. maximum. In Cone A of E. sylvaticum it is rather difficult to estimate the number of parenchymatous meshes that arise within the cone (i. e. above the sporangiophores), because in it the annulus is attached very close to the points of insertion of the lowest sporangiophores. The latter are disposed a little irregularly and at slightly different levels. As a result of the absence of elongation in the region between the annulus and the lowest fertile whorl the parenchymatous meshes arising by the supra-annular branching of the axial strands originate but very little below those arising above-in most cases but little above-the points of departure of the traces of the lowest sporangiophores. Thus, on a superficial examination of Text-fig. I, two of the meshes-those shown in the reconstruction as arising between and slightly below the first and fifteenth, and the second and third traces respectively of

${ }^{1}$ Such an explanation would not involve the attribution of any morphological value to the sheath, since the suggested modification in the direction of development is due to a purcly physiological character, the early increase in size of the cells of the sheath.

2 A somewhat analogous origin of ontogenetically centripetal from phylogenetically centrifugal xylem has been suggested by Chodat (1908) for the mesarch strands of Lyginodendron. 


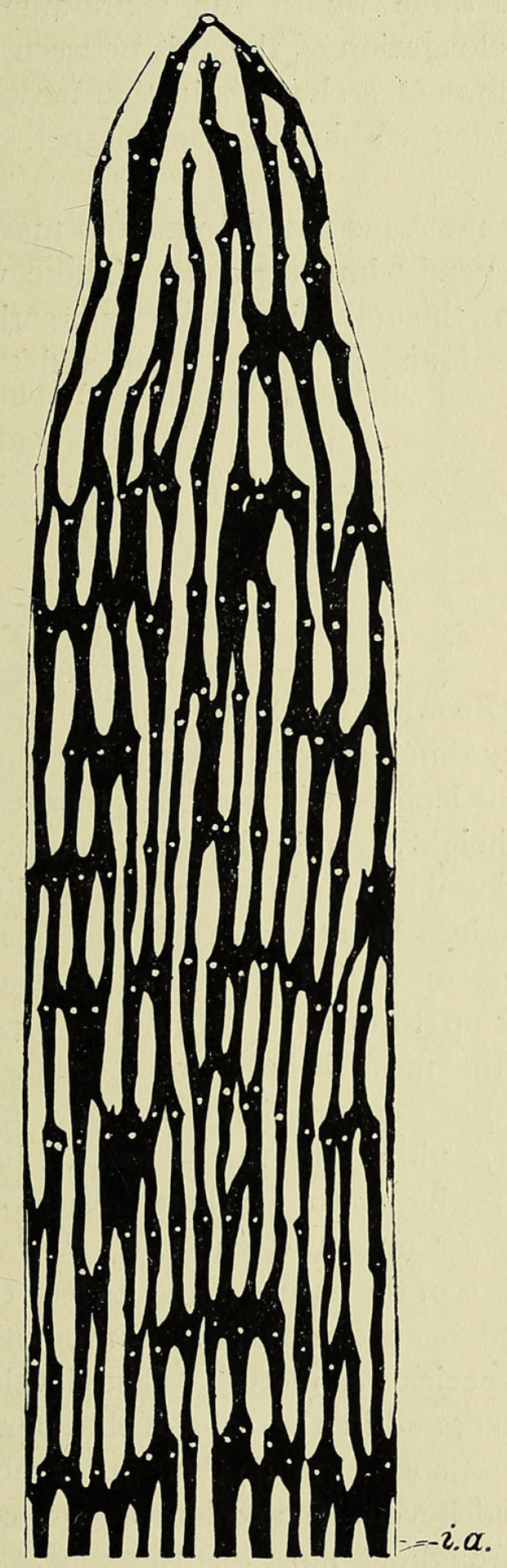

TEXT-FIG. I. Reconstruction of the stele of Cone A of E. sylvaticum. Axial xylem black; traces and parenchyma white; i.a., level of insertion of annulus. $\times 8$.

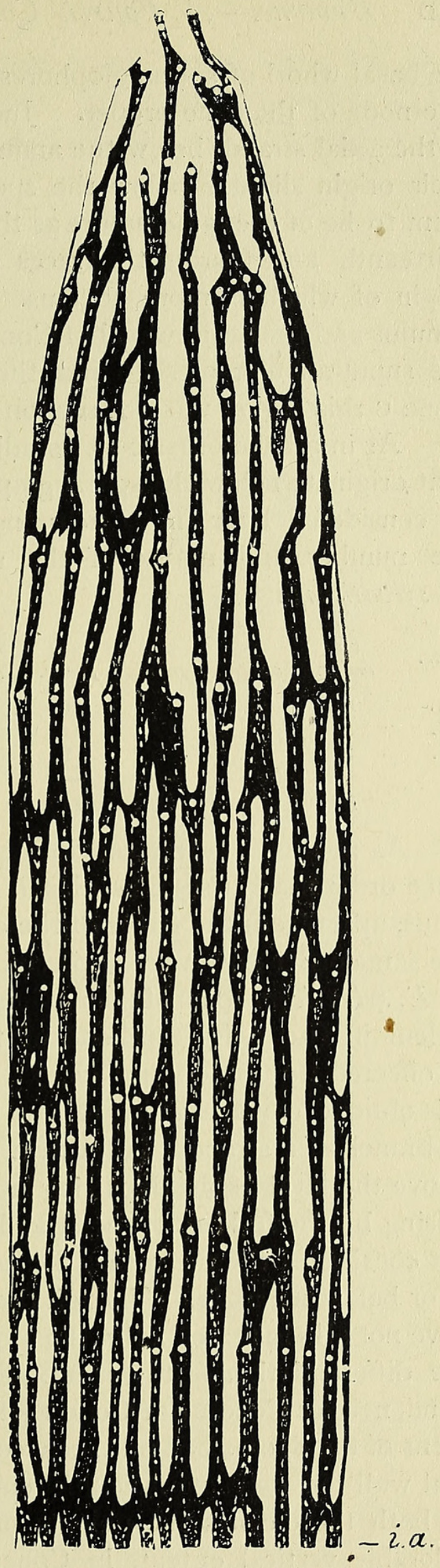

TExT-FIG. 2. Reconstruction of the stele of Cone B of $E$. sylvaticum. Axial xylem black ; traces and parenchyma white; protoxylem a broken line enclosing a dotted surface; i.a., level of insertion of annulus. $\times$ I0. 
the basal whorl of sporangiophores-might well seem to belong to the first internode of the cone proper. Judging, however, from their superposition to the axial strands below the annulus, from their alternation with and from their origin slightly below the sporangiophores, these two meshes would seem to be of the same nature as those between the ninth and tenth and the thirteenth and fourteenth traces of the same whorl, the supra-annular origin of which is more obvious. The elongation of the axis between the annulus and the basal whorl of Cone $\mathrm{B}$ allows of a clear distinction between the supra-annular meshes and those arising within the cone proper. In Cone $\mathrm{C}$ this region was not sectioned.

As in all the other cones studied by me some parenchymatous meshes that originate below the sporangiophores persist into the cone. These will be considered later on. Excluding them, the following table summarizes the number and nature of the meshes found in Cones $\mathrm{A}, \mathrm{B}$, and $\mathrm{C}$ of E. sylvaticum:

\begin{tabular}{|c|c|c|c|c|c|c|c|c|c|c|}
\hline Cone. & $\begin{array}{c}\text { Ist } \\
\text { order. }\end{array}$ & $\begin{array}{c}2 n d \\
\text { order. }\end{array}$ & $\begin{array}{c}3 r d \\
\text { order. }\end{array}$ & $\begin{array}{c}\text { 4th } \\
\text { order. }\end{array}$ & $\begin{array}{c}5^{\text {th }} \\
\text { order. }\end{array}$ & $\begin{array}{c}\text { 6th } \\
\text { order. }\end{array}$ & $\begin{array}{c}7_{\text {th }} \\
\text { order. }\end{array}$ & $\begin{array}{c}8 \text { th } \\
\text { order. }\end{array}$ & $\begin{array}{c}9^{\text {th }} \\
\text { order. }\end{array}$ & $\begin{array}{l}\text { Total } \\
\text { meshes. }\end{array}$ \\
\hline A. & I 7 & I3 & 9 & 6 & 4 & I & 0 & o & I & $5^{\mathrm{I}}$ \\
\hline B. & 10 & I3 & 2 & 2 & 0 & 2 & I & 0 & 0 & 30 \\
\hline C. & II & 7 & 6 & 6 & 5 & 5 & 0 & 0 & 0 & 40 \\
\hline & $\overline{38}$ & - & $\overline{17}$ & $\overline{\mathrm{I} 4}$ & $\overline{9}$ & $\overline{8}$ & $\bar{I}$ & $\overline{0}$ & $\bar{I}$ & I2I \\
\hline
\end{tabular}

As pointed out in a previous paper (Browne (2), p. 233), meshes of the same order may arise or be closed at very different levels in the internode. Thus, apart from the factor of the different lengths of internodes, meshes of the same order may vary appreciably in height, even in the same internode. In E. sylvaticum some of the meshes are closed by the formation of additional xylem in the neighbourhood of the node. In other cases the closure is effected by the oblique course of one or both branches of a strand, this oblique course leading a little higher up to fusion with another strand or branch of a strand. In such a case the mesh is only closed somewhat above the level of the departing trace and of the initiation of the new mesh arising by the forking of the strand. But, as in my previous papers, I have not considered the mesh thus closed as of a higher order than those closed at or below the node. Though the axes of Cones A, C, and D of E. debile have not all elongated fully, the appearance of the tissues made it clear that the differentiation of the metaxylem had been completed. On the other hand, neither Cone B nor Cone $\mathrm{E}$ of this species was mature. The development of the spores had not been completed, and in the cells of the sporangial wall the characteristic thickenings had not yet made their appearance. In both these cones the phloem projected beyond the xylem over a considerable vertical extent, in Cone $\mathrm{E}$ throughout most of the cone. To judge from mature cones, in which the metaxylem always extends laterally as far as and sometimes a little farther than the phloem, the full 
the Anatomy of the Cone and Fertile Stem of Equisetum. 433

differentiation of the metaxylem in these cones would have led to a further closure of parenchymatous meshes. In the reconstructions of the steles of Cones $\mathrm{B}$ and $\mathrm{E}$ of this species the phloem, where it projects be-

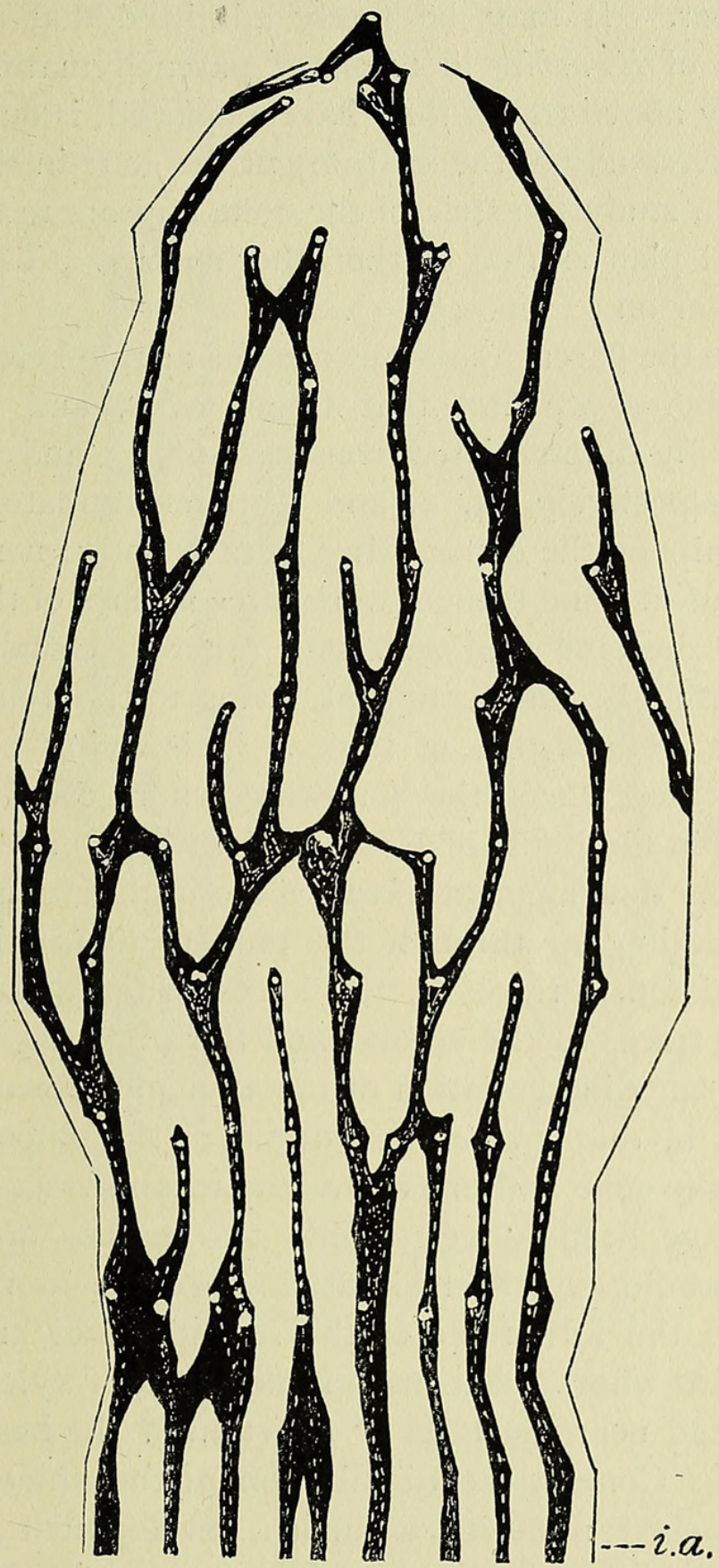

TEXT-FIG. 3. Reconstruction of the stele of Cone A of $E$. debile. Axial xylem black; traces and parenchyma white; protoxylem a broken line enclosing a dotted surface; i.a., level of insertion of annulus. $\times 13 \frac{1}{3}$.

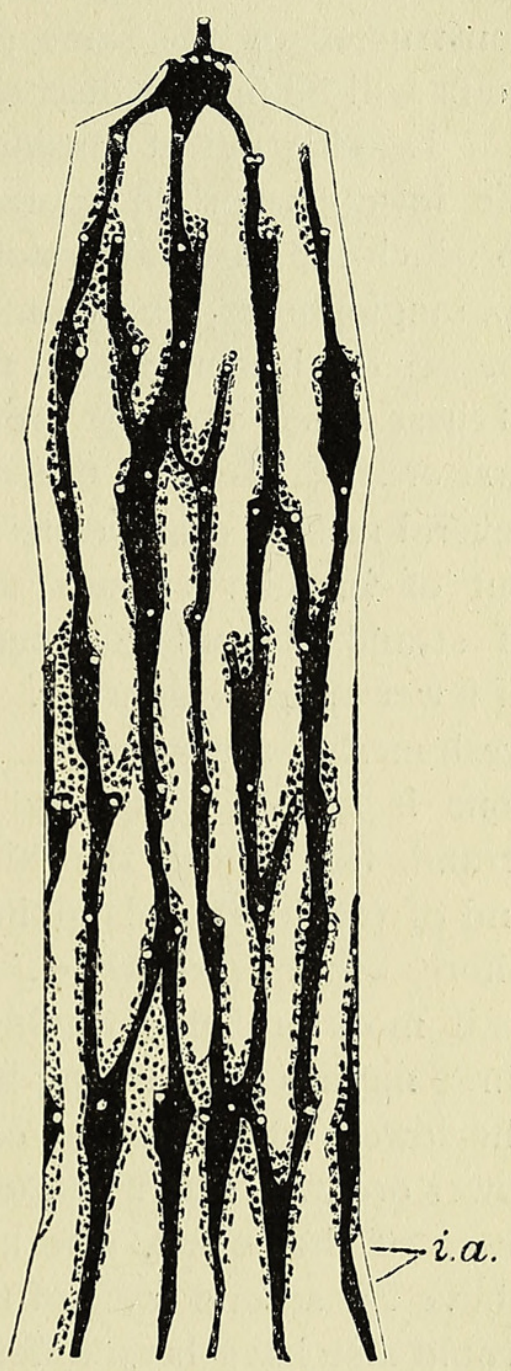

TEXT-FIG. 4. Reconstruction of immature stele of Cone B of $E$. debile. Axial xylem black; traces and parenchyma white. The broken line enclosing a dotted surface represents the outline of the phloem, where the latter projects beyond the xylem; i.a., level.of insertion of the annulus. $\times 20$.

yond the xylem, is shown by a broken outline, enclosing a dotted surface. The actual phases represented in the diagrams in no way correspond to a natural pause in the differentiation of the xylem. The transition from protoxylem to metaxylem is here very gradual. 


\section{Browne.-A Fourth Contribution to our Knowledge of}

As may be seen in Text-figs. 3-7 the vascular system of the cone of $E$. debile consists of a loose network of strands. The tracts of parenchyma are relatively wide, long, and irregular, and many of them originate below the cone proper. It may be freely admitted that an analysis of the stele of the cone of $E$. debile in terms of parenchymatous meshes, arising in the phylogeny above traces that have departed, is only possible by means of a comparative study of the anatomy of the cone in the genus. But in the light of such a study the stele of the cone appears to be constructed on the same general plan as that of the other species. This point will be further discussed later on (cf. pp. 450-I).

Leaving out of consideration the parenchymatous meshes arising below the lowest whorl of sporangiophores, we find that Cones A, C, and D, in which the vascular system is fully differentiated, consist of 68,35 , and $3^{2}$ sporangiophores, and contain respectively $\mathrm{I} 2,4$, and 5 parenchymatous meshes originating within the limits of the cones. In Cones $\mathrm{A}$ and $\mathrm{C}$ none of these was of the first order; but in Cone D there were three meshes of the first order. Most of the meshes become confluent with others. Usually several meshes originating separately become confluent, owing to the dying out of vascular strands after the departure of traces. This dying out of strands is not confined to cases where the following whorl consists of fewer sporangiophores. Within the limits of Cone B (Text-fig. 4) seven fresh meshes are initiated. But the development of two more in the mature cone is foreshadowed by the linking up through the phloem of $(a)$ the strands from which the third and fourth traces of the lowest whorl depart and of $(b)$ the strands giving off traces to the second and third sporangiophores of the third whorl. Had the differentiation of metaxylem followed, as it most probably would have in due course, the outline of the phloem three meshes (two arising below the cone and one above the second trace of the lowest whorl) would each have been converted into two meshes of a lower order. The new meshes would have been situated above the fourth trace of the lowest whorl, above the fifth trace of the second whorl, and above the second trace of the third whorl. A considerable width of xylem would also have been differentiated near the level of insertion of the basal whorl of this cone. Similarly, in Cone $\mathrm{E}$ the distribution of the phloem indicates that had the cone reached maturity a further development of metaxylem would probably have led, by the closure of a mesh originating below the cone, to the formation of a fresh mesh above the third trace of the lowest whorl. As it is, only one mesh actually originates within the limits of Cone $\mathrm{E}$, for it seems clear that the apparent initiation in Text-fig. 7 of a fresh mesh between the second and third traces of the fourth whorl is deceptive. It is due to the transference to paper of a transient phase; for the development of the later formed metaxylem would presumably have led to the filling in of the small gap between the two 
traces. The same remark applies to the small gap in the xylem between the fifth and sixth traces of the fourth whorl of Cone B (cf. Text-fig. 4).

It is characteristic of $E$. debile that a number of wide, long, parenchymatous meshes either remain enclosed throughout the whole cone (in which case the persistent meshes fuse around the base of the vascular strand of the acumen) or are only closed at or just below the apex of the cone, at the level of insertion of the closely approximated, often partially concres-

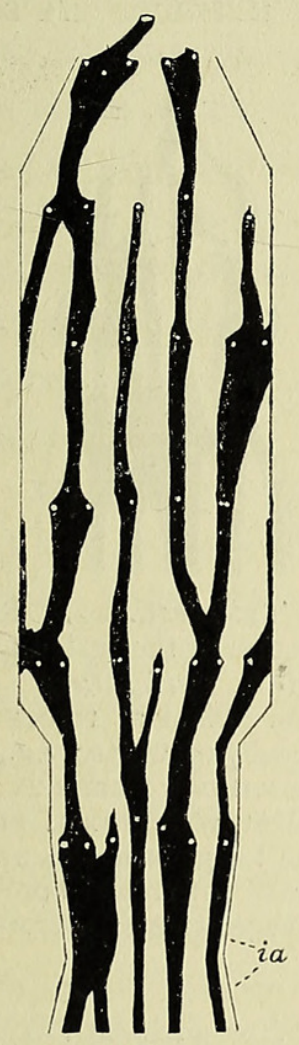

TeXT-Fig. 5. Recon. struction of the stele of Cone $\mathrm{C}$ of $E$. debile. Axial xylem black; traces and parenchyma white; i.a., level of insertion of annulus. $\times 10$.

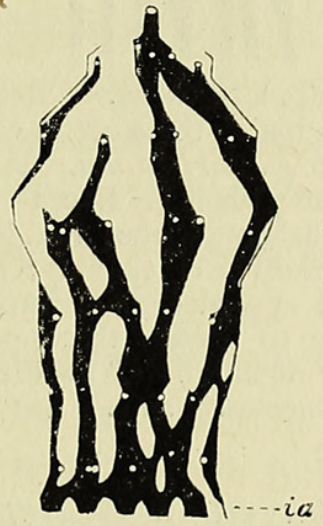

TEXT-FIG. 6. Reconstruction of the stele of Cone $\mathrm{D}$ of $E$. debile. Axial xylem black; traces and parenchyma white; i.a., in. sertion of annulus. $\times$ Io.

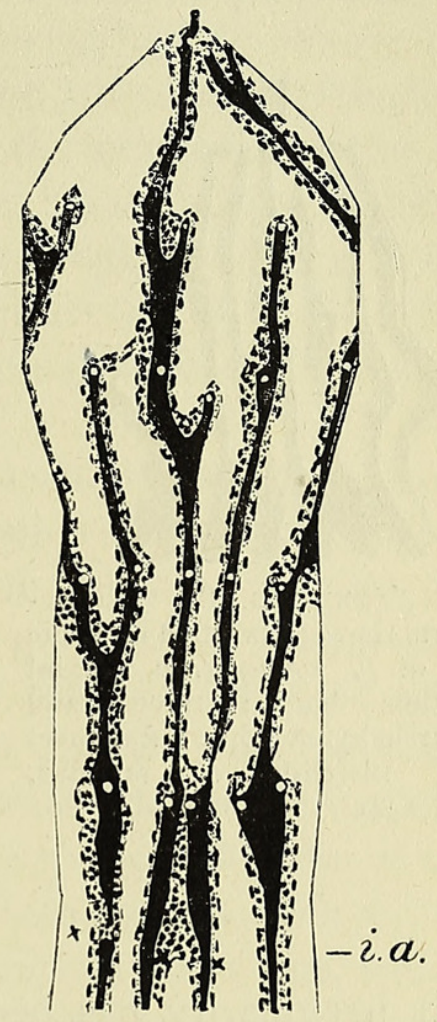

Text-Fig. 7. Reconstruction of immature stele of Cone $\mathrm{E}$ of $E$. debile. Axial xylem black; traces and parenchyma white. The broken line enclosing a dotted surface represents the outer limit of the phloem where the latter projects beyond the xylem; i.a. level of the insertion of the annulus. $\times 26 \frac{2}{3}$.

cent sporangiophores of the uppermost whorl. Indeed, except in Cone D, some of the meshes persisting into the apical region originate below the cone and annulus (cf. p. 445).

Only six fresh parenchymatous meshes originate within Cone A of $E$. variegatum. All of them remain unclosed, becoming confluent with one another and with two unclosed meshes arising below the cone and persisting through it. In Cone $\mathrm{B}$ of this species six meshes arose within the limits of the cone and only one, of the second order, was closed. In 


\section{Browne. - A Fourth Contribution to our Knowledge of}

Cone $\mathrm{C}$ there were seven distinct meshes arising within the cone, and there was also an indication of what might be regarded as a minute and deferred mesh, but is a mere local failure of a few elements to become tracheides. At this point, between the second and third whorls, the xylem is only separated by a single endodermal cell, common to both endodermes. Five of the meshes are closed, two being of the first and three of the second order. At the level of the third whorl one of the strands of Cone A passes through the node without giving off a trace. A simi-

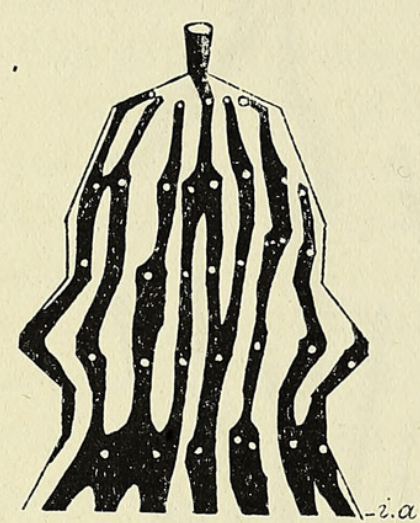

TEXT-FIG. 8. Reconstruction of the stele of Cone A of $E$. variegatum. Axial xylem black; traces and parenchyma white; i.a. level of insertion of annulus. $\times 13 \frac{1}{3}$.

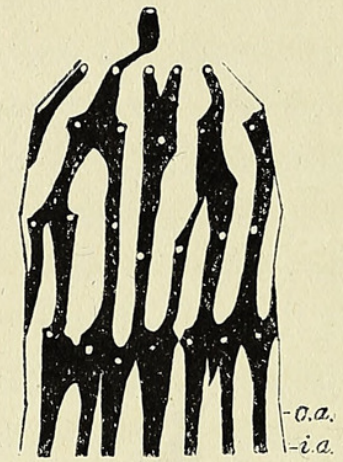

TEXT-FIG. 9. Reconstruction of the stele of Cone в of $E$. varieganm. Axial xylem black; traces and parenchyma white; $i . a$., level of insertion of annulus; $c . \alpha$., level at which axial bundles cease to present the appearance of internodal bundles of the vegetative axis. $\times I^{\frac{1}{3}}$.

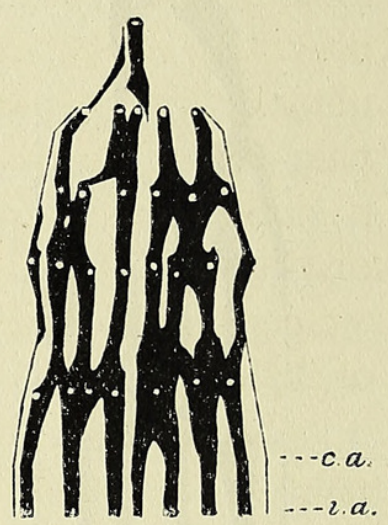

TEXT-FIG. IO. Reconstruction of the stele of Cone C of $E$. variegatum. Axial xylem black; traces and parenchyma white ; i.a., level of insertion of annulus ; c.a., level at which axial bundles, cease to present the appearance of internodal bundles of the vegetative axis. $\times \quad 3_{3} \frac{1}{3}$.

lar irregularity has been observed in E. limosum (Browne (1), pp. 678-9) and in E. maximum (Browne (2), Pl. XIII).

In $E$. variegatum, as in the other species studied, certain parenchymatous meshes originating below the cone persist into the iatter. These will be considered on a later page.

\section{The Apex of the Cones.}

In Cones $\mathrm{A}$ and $\mathrm{C}$ of E. sylvaticum the apex of the cone is traversed by a single strand, resulting from the fusion of two persistent vascular strands. At their junction these two strands enclose a few parenchymatous cells, but during the narrowing of the terminal strand, which follows rapidly on its constitution, these disappear, and the xylem forms a solid strand, more or less circular in transverse section. The structure in these cases is very similar to that found in the apices of the cones of E. maximum (Browne (2), p. 242). In Cone B, on the other hand, two strands lying a certain distance apart in the parenchymatous ground tissue persist into the 'drip-point' of the cone. The extreme apex of the latter had been injured, and it was not 
possible to ascertain whether the two strands became confluent, but as they were relatively far apart, it is likely that they remained separate, at least for some distance (cf. apex of cone in E. arvense, Browne (1), p. 683).

In Cones A, C, and D of E. debile the stele near the apex is relatively wide, and the traces of the uppermost sporangiophores depart from two more or less widely separated vascular strands. In Cone A the two strands, much narrowed above the departure of the traces, soon fuse to form the vascular supply of the terminal acumen. In Cones $C$ and $D$ the narrower of the two axial strands dies out, and the other, after narrowing rapidly above the departure of the traces, enters the acumen. In Cone B the traces of the four more or less concrescent sporangiophores found at the apex of the cone depart from a closed or rapidly closing ring of xylem, recalling that found in a similar position in E. palustre (Browne (1), p. 683). In Cone $\mathrm{E}$ the distribution of the phloem indicates that had the differentiation of the metaxylem been complete a similar condition would have prevailed at the apex of the cone.

In Cones $\mathrm{A}$ and $\mathrm{B}$ of $E$. variegatum all the vascular strands except one pass out in their entirety as traces of the sporangiophores of the uppermost whorl. One strand, though giving off a trace of the same size as the others, persists and passes into the acumen. After giving off a trace it is at first very narrow, but it rapidly widens again and remains for some time markedly wider than were the strands a little lower down. In Cone $\mathrm{C}$ the structure of the apex is somewhat different. The tracheides of the vascular strands of the acumen, though they approach very close to one of the vascular strands of the axis, do not actually come into contact with any of them. All the bundles of the axis pass out as traces, except one, which, though giving off a trace similar to the other traces, persists as a very narrow strand. This narrow strand approaches the main vascular supply of the acumen, but does not fuse with it, and dies out before it. The structure of the apex in this specimen appears to be slightly anomalous. It seems likely that the want of continuity between the tracheides of the acumen and those of the axial strand they approach is due to an accidental and purely local failure of a few cells to develop as tracheides.

\section{The Sporangiophores and their Vascular Supply.}

The stalks of the sporangiophores of E. sylvaticum are relatively long and slender, and, excluding the partially concrescent members of the uppermost whorl, concrescent sporangiophores are rare, probably because, owing to the slenderness of their stalks, they are not so liable to be disposed in close proximity to one another. In Cone B, however, the first and second and the tenth and eleventh sporangiophores of the eighth whorl are respectively basally concrescent in pairs. It is possible that the occurrence in a single whorl of two pairs of basally concrescent sporangiophores should 


\subsection{Browne. - A Fourth Contribution to our Knowledge of}

be brought into relation with the fact that whereas the stele has diminished in width the whorl contains one member more than the whorl below.

The traces of the sporangiophores in this species are very small. ${ }^{1}$ When passing through the cortex they usually consist, as seen in transverse section, of five to nine tracheides. In the stalk the vascular strand remains slender until close to the peltate head, where, before it divides into radiating branches, the tracheides increase considerably in number. In mature cones the lower sporangiophores are often markedly reflexed, but the traces passing through the cortex are not deflected downwards, or only very slightly so towards its outer edge. The traces, other than those of the lowest whorls, pass obliquely outwards and upwards, though all the traces show a tendency to be slightly 'bowed' near their point of departure from the axial stele. Cases in which the trace of a sporangiophore is prematurely divided, so that two separate bundles enter a sporangiophore, single in nature, are not uncommon in this species (e. g. the traces of the first sporangiophore of the fourth and of the fifth sporangiophore of the eighth whorl of Cone A ; those of the tenth sporangiophore of the second, of the eighth sporangiophore of the fourth, and of the seventh sporangiophore of the ninth whorl of Cone B). In other cases the trace, though not bifascicular at its origin, arises deeply lobed and divides in the cortex or in the proximal part of the sporangiophore (e. g. the thirteenth trace of the seventh and the first trace of the ninth whorl of Cone A) (cf. p. 454).

In the reconstruction of the stele of Cone $\mathrm{B}$ a small white cross may bc seen at the level of the second whorl. The third sporangiophore of this whorl is hardly, if at all, wider than its neighbours; but it is traversed by two independent, approximated strands. One of these is the third trace of this whorl as shown in the reconstruction; the other strand dies out in the cortex without reaching the axial stele, and the white cross marks the level at which and the radius on which its last tracheide dies out. In Cone A one of the strands passes through the level of the third whorl without giving off a trace. The tracheides of the vascular supply of the sporangiophore opposite this strand pass inwards until they come into contact with the phloem of the axis, but die out without joining on to the tracheides of the axial bundle. The phloem of the sporangiophore is continuous with that of the axis. Similar variations from the normal have, it will be remembered, been observed in E. maximum (Browne (2), pp. 247-8).

In $E$. debile the sporangiophores have short, relatively wide stalks. Varying degrees of concrescence are not uncommon (e.g. the fourth and fifth sporangiophores of the eighth whorl of Cone A; the fifth and sixth sporangiophores of the third whorl of Cone $\mathrm{C}$; the first and second sporangiophores of the fourth whorl of Cone D, and the fifth and sixth

1 In the reconstructions of the stele it has been necessary, for the sake of clearness, slightly to exaggerate the size of the traces of the sporangiophores. 
ones of the second whorl of Cone E). Prematurely divided traces also occur (e.g. those of the first sporangiophore of the third whorl of Cone B, and of the second sporangiophore of the lowest whorl of Cone D). The traces of the third, fourth, and fifth sporangiophores of the third whorl and of the fifth sporangiophore of the fourth whorl of Cone A originate as deeply lobed bundles which fork almost at once.

The sporangiophores of $E$. variegatum, though small, have relatively long, slender stalks. Only two examples of concrescence of sporangiophores were observed outside the apical region; the seventh and eighth traces of the fourth whorl of Cone A, and the fifth and sixth traces of Cone B entered pairs of nearly completely concrescent sporangiophores. The third trace of the latter whorl supplied an unusually large sporangiophore, apparently single in nature, though intermediate in size between the double sporangiophore and the other sporangiophores of this whorl.

\section{The Region transitional From Stem to Cone.}

In $E$. sylvaticum parenchymatous cells are less freely distributed in the axial metaxylem in the region of insertion of the annulus (P1. XXI, Fig. I). Here the metaxylem is also usually of greater radial extent, and consists in part of rather wider tracheides. In Cone B, particularly, some of the tracheides in this region strikingly recall in size and form those of the nodal (or supranodal) wood, certain of them even possessing reticulate thickenings. No reticulately thickened tracheides were found at the corresponding level of Cones $\mathrm{A}$ and $\mathrm{D}$, and the sections of Cone $\mathrm{C}$ did not include this region. The protoxylem is somewhat disorganized at this level, although definite carinal canals have disappeared or are disappearing. Higher up, canals, smaller and less definite than those of the internode below the annulus, make their appearance. In Cone $\mathrm{A}$ the region between the insertion of the annulus and the basal whorl of the cone has elongated very little, and the amount of axial xylem at the level of the departure of the traces of the lowest sporangiophores remains greater than is general in the cone, though the tracheides are less numerous, and more parenchymatous cells are interspersed among them than immediately below, where the supra-annular anastomoses occur. In Cones $\mathrm{B}$ and $\mathrm{C}$, where the region between the annulus and the sporangiophores has elongated considerably, there is, when we reach the insertion of the sporangiophores, no unusually large amount of axial metaxylem.

In the reconstruction of the stele of Cone $\mathrm{B}$ a small white cross may be seen near the lower end of the sixth strand. At this point two tracheides protrude from the stele, as though they formed part of a trace. They are accompanied by two or three phloem-like and endodermal cells, oriented in the same way, i. e. with their long axis directed at right angles to those of the corresponding cells of the bundle. The cells of this incipient trace 
never become free from those of the axial bundle, and a few sections higher up the latter has resumed its normal appearance.

Above the last whorl of leaves the cone-bearing branch of $E$. debile is at first smooth and unribbed. In the two axes bearing the mature cones $\mathrm{A}$ and $\mathrm{C}$ the grooving soon reappears, the ribs being in fact particularly prominent. But, unlike the other ribbed axes of Equisetum, the ribs are opposite the vallecular canals, and the grooves opposite the bundles (cf. P1. XXI, Fig. 6). ${ }^{1}$

Though Milde records (p. I35) the occurrence of stomata on the dorsal and more rarely on the ventral side of the leaf-sheaths he does not mention their presence on the annulus. In Cone B of $E$. debile, however, the upper surface of the annulus bore several stomata (Pl. XXI, Fig. 9). Though this species belongs to Milde's Equiseta cryptopora, characterized by a very regular arrangement of the stomata, those of the annulus appear to be few and irregularly distributed.

In Cones $\mathrm{A}, \mathrm{B}, \mathrm{C}, \mathrm{D}$, and $\mathrm{E}$ of $E$. debile the region transitional from branch to cone shows a rather wide range of variation. In Cones $\mathrm{A}$ and $\mathrm{D}$ there are, in the internode below the annulus, respectively nine and five vascular strands. These have arisen in the manner usual in the genus, i. e. by the breaking up of the ring of nodal or supranodal xylem into bundles equal in number to and alternating with the uppermost leaf-traces. But in Cone B there were only five strands throughout the greater part of the internode below the annulus, although the last whorl of leaves and the first whorl of sporangiophores both consisted of eight members. A sixth strand was, indeed, constituted, but it died out almost at once. Over two of the leaftraces no fresh parenchymatous mesh arose, but owing to the rapid widening of the five existing meshes as they pass upwards, all the strands soon become narrow bundles, much of the same size. In Cone $\mathrm{c}$ of E. debile, where the last foliar whorl consisted of six, and the basal whorl of the cone of seven members, there were only five strands in the internode below the annulus. This is due to the fact that at the last node of the branch the ring of reticulate tracheides was not complete. A parenchymatous mesh, though markedly narrowed at the node, persisted through the latter. Consequently the traces on each side of the mesh were very near the edges of the band of xylem; above their departure the mesh between them widened again, but no fresh meshes were formed. A like failure to form a complete ring of wood at the last node of the branch bearing Cone $\mathrm{E}$ and a similar structure above the traces next to the persistent mesh account for the reduction of the vascular strands to four in the infra-annular internode of Cone $\mathrm{E}$, in which

1 Duval-Jouve (p. 190 and P1. V, Fig. I3) states that in the obscurely ribbed rhizome of $E$. littorale the carinal canals lie opposite the grooves and the vallecular canals opposite the ribs. According to his description the large size of the vallecular canals appears to cause the tissues external to them to be pushed outwards, so as to simulate a blunt rib. Milde, however, after examining numerous specimens, was unable to confirm this observation (Milde, pp. $3^{\text {fo-I }}$ ). 
the uppermost whorl of leaves and the basal whorl of the cone alike consist of five members. This failure to form a closed ring of xylem at the last node of the branch is clearly due to vascular reduction, not a surprising conclusion when we remember how reduced a vascular system is the network of strands constituting the stele of the cone of this species.

In Cone $\mathrm{E}$ the annulus, as seen in transverse sections of the axis, showed four very small groups of 2-4 tracheides running obliquely, but nearly horizontally, upwards through its parenchyma. None of these tracheides was in connexion with the tracheides of the axis, nor were the narrow, parenchymatous, phloem-like and endodermis-like cells that accompanied them and had a like orientation with them in connexion with the corresponding elements of the axial stele (Pl. XXI, Fig. 3). The latter type of cell, however, approached closer to the stele than the tracheides. As the limits of the annulus and axis are not sharply defined, it is difficult to say how far, if at all, the annular bundles penetrate the axial parenchyma. As Miss Barratt has shown that the first tracheides of the leaf-trace to be differentiated are situated distally, and that lignification proceeds in the direction of the axis (Barratt, p. 207), it might be thought that, in view of the immaturity of Cone E, these small annular bundles would later have become connected with the stele of the axis. But, apart from the fact that the specimen is not young enough to show so incomplete a stage of development, the inner termination of the annular tracheides was usually marked by the presence of endodermis-like cells, cutting the annular tracheides off from the axial stele. In the reconstruction (Text-fig. 7 ) these small free, annular bundles (cf. Browne (3), p. 254) are shown as small crosses, white on black and black on white, on the strands and meshes at the level and on the radius of their dying out. ${ }^{1}$

Miss Barratt states that though the vascular structure does not support the view that the annulus is of foliar nature it cannot be said to throw much light on the morphology of that organ. The arguments she gives against the foliar nature of the annulus are, firstly, the course of the protoxylem strands in the region of its insertion, and secondly, the total absence from it . of vascular supply. The latter argument she admits not to be an insuperable objection to the foliar theory, "because the ochreola which occurs at the base of all branches always lacks traces' (Barratt, p. 228). As a matter of fact the ochreola is not always completely devoid of vascular elements, ${ }^{2}$ but, since it is usually devoid of vascular supply, the absence of traces from the annulus is, as Barratt recognizes, no insuperable objection to its being regarded as a reduced leaf-sheath. Moreover, in two cones of

1 The white cross, which should be shown on the first strand of Text-fig. 7 , is unfortunately almost undistinguishable.

2 Milde in 1867 recorded the occurrence of a few tracheides in the ochreola of $E$. arvense and E. limosum (pp. I 57 and 346 , Pl. II, Fig. 36), while in 1876 Janczewski indicated, in a reconstruction of a node, the presence of vascular tissue in the ochreola of $E$. arvense (Janczewski, Pl. II, Fig. 9). 
$E$. hyemale a trace has been described passing out from the stele into the cortex at the level of the supra-annular anastomoses, though, owing to the destruction of the external tissues, it could not be ascertained whether these traces died out in the cortex or penetrated the annulus (Browne (3). p. 253). The protrusion into the cortex of two tracheides and of a few cells resembling phloem and endodermis opposite the insertion of the perfectly normal annulus of Cone B of $E$. sylvaticum may possibly be an indication of a vestigial node. The exceptional radial extent and the character of the metaxylem in this cone and the small groups of vascular cells in the annulus of Cone $\mathrm{E}$ of $E$. debile may also be vestigial nodal characters.

Of the course of the protoxylem Barratt writes: 'The protoxylem strands from the internode pass without any disjunction to the level at which the first sporangiophore traces arise, and hence there is no alternation at the so-called "node". There may be apparent forking of the strands, but this is due to the fact that the protoxylem strands in the bundles of the internode below are often double, which, separating as they enter the cone, produce this appearance of forking. This appearance is emphasized by the disposition of the metaxylem at this region, which is similar to that of the so-called nodes from which the sporangiophore traces arise' (Barratt, p. 228).

Of course, if the cases of separation of double protoxylems alluded to by Barratt occurred in specimens in which the number of sporangiophores was greater than the number of leaves at the last vegetative node little significance can be attached to them, since forking of the strands (preceded by forking of the protoxylem) is the most natural manner of effecting such an increase. Forking of this kind is found in the ordinary axes when an increase occurs in the number of members in successive whorls (Browne (2), pp. 257-8). But otherwise the presence of double protoxylem strands below the cone would seem to show that the preparation for the branching of the strand began with the branching, somewhat lower down, of the protoxylem, a very common procedure in branching bundles or meristeles. For, as Barratt points out, there is below the annulus an 'undoubted internode' (Barratt, p. 228), and we must presume that its strands arose in the usual way, above and between the uppermost whorl of leaves. ${ }^{1}$ If so, they originated as equivalent bundles, each with a single strand of protoxylem, the position of which is marked in the internode by a carinal canal. The branchings of the protoxylem, about to be described for E. sylvaticum, occur slightly above the insertion of

1 The bundles of the peduncle-as the axis between the last whorl of leaves and the annulus is called-seem typically to arise in exactly the same way as the bundles in the other vegetative internodes. I have examined a considerable number of specimens, belonging to seven species, and the only real difference that I was able to observe was that in the more reduced specimens of $E$. debile irregularities occurred, owing to the ring of xylem being incomplete at the last vegetative node (cf. pp. 440-I). 
the annulus, between this level and the forking of the metaxylem strands. We may thus conclude that the forking of the protoxylem, whether it occurs somewhat below or a little above the insertion of the annulus, is probably, like the forking of the metaxylem, a reminiscence of a former node. Another explanation of the early division of the protoxylem would be that if the annulus is a reduced leaf-sheath only the free part is developed, the basal part being presumably concrescent with the axis.

In Cones $\mathrm{A}$ and $\mathrm{B}$ of $E$. sylvaticum the supra-annular anastomoses are relatively numerous. ${ }^{1}$ Among the species studied the only one which shows a proportion of such anastomoses at all comparable to that of E. sylvaticum is E. hyemale (Browne (3), pp. 242-3 and Text-figs. 2-4). In Cone B of E. sylvaticum eleven out of thirteen parenchymatous meshes are closed slightly above the insertion of the annulus and eleven fresh meshes arise, one of the first, one of the second, three of the third, two of the fourth, three of the fifth, and one of the ninth orders. In Cone $\mathrm{A}$ of this species nine out of twelve parenchymatous meshes are closed slightly above the insertion of the annulus. As already indicated (p. 432), I interpret the two parenchymatous meshes arising slightly below and to one side of the first and second traces of the lowest whorl of this cone as supra-annular in origin. This interpretation gives five meshes as originating above the annulus, two of the first and three of the second order.

As the basal whorl of Cone A of E. sylvaticum consists of fifteen sporangiophores, and there are only twelve bundles in the lower part of the internode below the annulus, the forkings of the protoxylem and metaxylem in the neighbourhood of the insertion of the annulus of this specimen do not afford so good an argument in favour of the presence of a vestigial node as do the corresponding anastomoses in Cone $\mathrm{B}$, where the lowest whorl of the cone consists of thirteen sporangiophores, and there are thirteen bundles in the internode below the annulus. Moreover, in Cone B the greater elongation of the region between the insertion of the annulus and the lowest sporangiophores makes the relations of the strands to one another particularly easy to follow. Though there are, of course, slight differences in size between the bundles and their carinal canals, of which each bundle possesses one, it seems clear that the thirteen bundles of the internode below the annulus are equivalent, and arose in the usual way above and between an equal number of leaf-traces given off at the whorl below. Nevertheless, but one strand of Cone B passes unbranched through the

1 It is interesting to note that according to Milde the branches, which are produced after the maturity of the cone by the originally unbranched fertile stems of E. sylvaticum, often develop immediately below the annulus (Milde, p. 288). Duval-Jouve writes (p. 147) that this anomaly is rather rare in France, but is presumably much more frequent in Switzerland, since Bernoulli, always so accurate, mentions the presence of branches below the annulus as a distinctive character of $E$. sylvaticum. This phenomenon, whether rare or common, appears to be a further indication of the less great reduction of the annulus in this species compared with most others. 
vestigial annular node; its protoxylem is also unbranched. Anastomoses occur between the twelve other strands, and when the bundles are reconstituted they alternate with those below the level of the anastomoses. In the cases of the two strands abutting on the two persistent meshes the alternation is of the type I have called irregular (Browne (1), pp. 68I-2); but the phenomenon is very distinct. The protoxylem of the branched strands also shows indications of forking (cf. Pl. XXI, Fig. 2). In the cases of the first, fourth, fifth, sixth, seventh, tenth, and thirteenth strands of the diagram (Text-fig. 2) one of the forks of the protoxylem dies out without effecting a junction with a neighbouring fork. In the cases of the first, fourth, fifth, sixth, tenth, and thirteenth strands the very short forks of protoxylem that die out cannot be clearly shown in the reconstruction, owing to the small scale of the diagram ; but in all these cases there is a perfectly distinct, short, divergent tooth of protoxylem. Both forks of the protoxylem of the third strand of the diagram and a fork of the second, seventh, tenth, twelfth, and thirteenth strands fuse with the forks of neighbouring protoxylem strands. It seems natural to regard the cases in which a fork of the protoxylem dies out without effecting a junction with a neighbouring fork as due to reduction, the reduction being greater or less according to the length attained by the fork before dying out.

In Cone A of E. sylvaticum three short branches of protoxylem (each one of a pair of which the other member persists) end blindly in the metaxylem above the insertion of the annulus. These short branches range from $150 \mu$ to $400 \mu$ in length. Since they die out in the metaxylem they are presumably unconnected with the increase in number of the sporangiophores (and consequently of the strands of protoxylem) over the leaves of the uppermost node. In these cases the forking of the protoxylem occurs a little way (about 400-600 $\mu$ ) above the insertion of the annulus, and the forks die out at about the level of and to one side of a neighbouring supraannular parenchymatous mesh, formed by the branching of a strand.

As regards the supra-annular anastomoses the five cones, A to E, of $E$. debile show marked differences. In Cone A three of nine parenchymatous meshes are closed somewhat above the insertion of the annulus, and one fresh mesh (of the fourth order) arises. In Cone B one fresh mesh (of the fifth order) originates above the insertion of the annulus. As seen in the diagram (Text-fig. 4) none of the parenchymatous meshes of this cone was closed at this level, but from the distribution of the phloem we may conclude that had the cone reached maturity the mesh between the third and fourth strands would have been closed by the differentiation of additional metaxylem. In Cone $\mathrm{C}$ one of five parenchymatous meshes is closed near the level of insertion of the annulus. No clear case of the origin of a supra-annular mesh is found in this cone. That arising between and slightly below the second and third traces of the lowest whorl may equally 
well be looked upon as supra-annular in origin or as having become, speaking phylogenetically, decurrent slightly below the trace of the sporangiophore, with the formation of which it may be associated. Such decurrence of meshes below traces is not uncommon in the cones of certain species (cf. Browne (2), p. 235).

It is in Cone $\mathrm{D}$ of this species that the anastomoses characteristic of the strands of the axis at the level of the annulus are most clearly shown. In Cone $\mathrm{D}$ four out of six meshes are closed in this region, and three fresh ones arise, one of the first, one of the third order, and one that persists unclosed throughout the whole cone.

In the matter of supra-annular anastomoses Cone $\mathrm{E}$ represents a much reduced condition. No fresh meshes arose in this region, and in the immature phase of development represented in Text-fig. 7 none was closed; but the distribution of the phloem indicated that had the metaxylem reached its full development the mesh between the second and third strands would have been closed in the neighbourhood of the insertion of the annulus.

It is characteristic of the cones of $E$. debile, other than Cone $\mathrm{D}$, that some of the meshes originating below the cone, and persisting in it, extend upwards throughout the greater part of the length of the cone. Thus, in Cone $\mathrm{A}$ one of the meshes arising above the uppermost vegetative node is only closed at the level of the uppermost whorl of sporangiophores. Cone $\mathrm{C}$ affords the most extreme example of unclosed meshes. Only three meshes arise within the cone, two of them unclosed, and one above the annulus, also unclosed. Four of the five parenchymatous meshes found in the internode below the annulus enter the cone, and three of them persist right through it and become confluent round the vascular strand of the acumen. One of these meshes has persisted unclosed not only through the whole cone, but also through the uppermost vegetative node (cf. p. 435).

In the cones of $E$. variegatum, of which serial transverse sections were prepared, no fresh parenchymatous meshes arose in the stele between the level of insertion of the annulus and of the sporangiophores. In Cones A and $\mathrm{B}$ none of the parenchymatous meshes originating above the leaf-traces of the last vegetative node was closed in this region. It is possible that the junction of the fourth and fifth strands near the bottom of the reconstruction of the stele of Cone $\mathrm{C}$ represents a supra-annular fusion, for the anastomoses of the strands associated with the insertion of the annulus frequently occur somewhat above the attachment of the latter.

It should be noted that in Cones $\mathrm{A}$ and $\mathrm{C}$, though there are seven sporangiophores in the basal whorl of the cone, and seven strands below the annulus (these strands having arisen above and between seven leaf-traces), the seven traces entering the sporangiophores are not given off each by a single strand of the internode below, as would have seemed likely in the absence of any clearly supra-annular branchings of the strands. On the 


\section{Browne.-A Fourth Contribution to our Knowledge of}

contrary, in Cone A a complex of three strands gives rise to two traces, while two more traces depart from a single strand; and in Cone $\mathrm{C}$ three traces depart from a complex of two strands, while another complex of two strands gives off but a single trace. Consequently, in these two cones (though not in Cone B) the traces of about half the sporangiophores of the lowest whorl are anatomically superposed, though somewhat irregularly so, to the corresponding leaf-traces of the last vegetative whorl. At the base

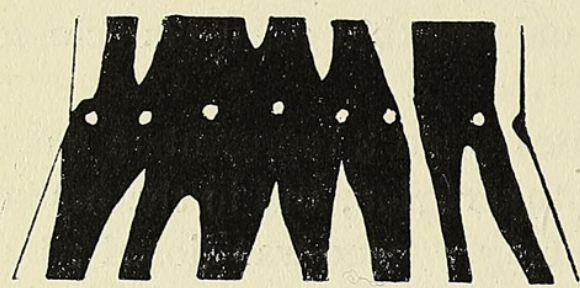

TEXT-FIG. II. Reconstruction of stele of Cone D of $E$. variegatum from below insertion of annulus to a point above level of first whorl of sporangiophores. Axial xylem black ; traces and parenchyma white. $\times 20$. of Cone D this superposition of the sporangiophore-traces to leaf-traces was also noticeable (cf. Text-fig. I I). It is possible to see in this condition the last indication of the existence in the ancestors of $E$. variegatum of anastomoses marking the former presence of a node, now obsolete, at the insertion of the annulus. Such an interpretation is admittedly very doubtful, and were it not for the numerous anastomoses found in other species in the neighbourhood of the insertion of the annulus - anastomoses that lead to an irregular superposition of some of the traces of the sporangiophores to certain of the leaf-traces-and for other indications of an obsolete or obsolescent node at this level, the point would not have been mentioned at all.

\section{General Considerations.}

Barratt, in a recent paper, has formulated certain generalizations concerning the cone and annulus of Equisetum which seem to me to rest upon an insecure foundation. While refraining from discussing the morphological nature of the sporangiophore, which is too wide a question to be conveniently treated in this paper, I shall, therefore, quote and comment upon some passages from her paper. But before doing this I wish to acknowledge the inadequacy of the description of the xylem of the cone given in my paper on Equisetum arvense (Browne (1), p. 666) and quoted in part by Barratt. The quotation as given by Barratt runs as follows: "She ${ }^{1}$ states (1, p. 666), "In a good many places there are internally to the bands or ring ${ }^{2}$ isolated tracheides or little groups of tracheides, usually of small size. ... Such tracheides or groups of tracheides do not as a rule persist for any considerable distance in a vertical direction ; in the internode they occur also internally to the separate strands of xylem." Barratt adds: "It may be stated quite definitely that these elements belong to the protoxylem, although Browne does not apparently identify

$$
1 \text { i. e. the present writer. }
$$$$
2 \text { i. e. of xylem. }
$$ 
them as such, and, as will be shown below, they form a definite system of strands, and constitute the scaffolding on which the whole vascular system of the cone is built up' (Barratt, p. 222). As a matter of fact the little groups of tracheides referred to in my description are undoubtedly protoxylem; but some of the isolated tracheides clearly represent scattered metaxylem elements, slightly internal to the main bands of metaxylem These single cells are quite irregularly scattered, and do not usually persist for any distance; not being disorganized, as are the tracheides of the protoxylem, they were presumably differentiated later than the latter. As my original description and a similar description of the corresponding tracheides in E. maximum (Browne (2), p. 234) not only failed to distinguish between the slightly more internal cells of the metaxylem and the protoxylem, but also failed to recognize the continuity of the strands of protoxylem, they were not only inadequate, but misleading. Barratt's conclusion that the system of protoxylem strands represents the scaffolding on which the whole vascular system of the cone is built up will be discussed later.

'As seen in transverse sections (Text-figs. 20 and 21) the metaxylem is separated from the protoxylem by parenchymatous cells ...' (Barratt, p. 223). This statement concerning the axis of the cone, taken from Barratt's paper, is too sweeping a generalization. In E. maximum, it is true, the internodal protoxylem of the

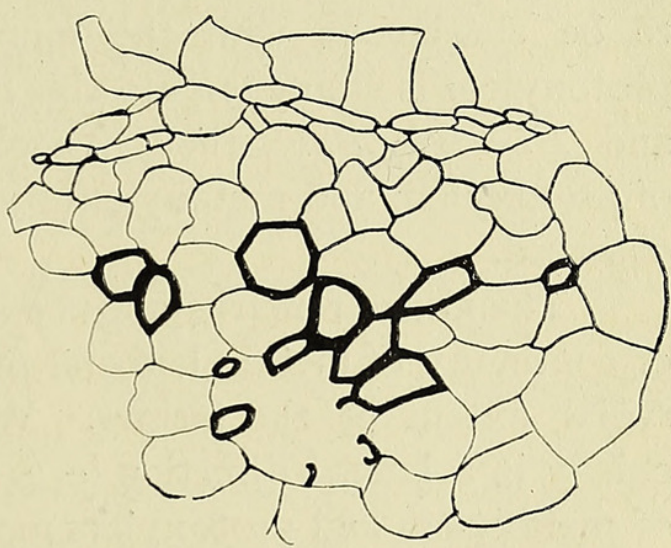

TEXT-FIG. I2. Section of internodal bundle from the axis of the cone of E. limosum, showing continuity of some of the metaxylem with the protoxylem. $\times c .45^{\circ}$. cone seems to be constantly separated from the metaxylem by parenchymatous cells. But in the bundle of E. palustre figured by Barratt in her Text-fig. 20 certain tracheides abut on the carinal canal, so that the protoxylem was presumably in contaçt with cells that develop as metaxylem. Metaxylem tracheides abutting on the carinal canals are also shown in figures of the internodes of the cone of E. palustre in my first paper on Equisetum (Browne (1), P1. LXV, Fig. 7). In the cone of E. limosum, so far as I have been able to observe, the protoxylem of the internodal strand is nearly always in contact with the metaxylem. This relationship is shown in Fig. 8 of Pl. LXV of my first paper on Equisetum (Browne (1)), and on a larger scale in Textfig. I2 of the present paper, representing a transverse section of a small bundle in the internode of the cone of this species. As parenchymatous cells are interspersed in the metaxylem, one or two of the former may be situated between part of the metaxylem and protoxylem, but, as stated 
above, the protoxylem seems to be generally in contact with part of the metaxylem. In $E$. arvense, in which the tracts of parenchyma separating the internodal strands of the cone are relatively narrow, the metaxylem develops chiefly in a lateral direction, and is of slight radial extent, so that it is usually separated from the protoxylem by parenchymatous cells. But in this species I have observed that in certain bundles metaxylem tracheides are in contact with the carinal canal for a considerable part of the internode. In E. hyemale and E. sylvaticum the relations between the protoxylem and the metaxylem in the cone vary between continuity and separation. In E. sylvaticum (in my specimens at least) the protoxylem usually abuts on the metaxylem, but in E. hyemale either condition seems about equally common. Often in a single section of a bundle the metaxylem abuts. on one of the sides of the carinal canal, and is separated from the other by a parenchymatous cell. In E. giganteum, in which the metaxylem is of relatively considerable depth, the protoxylem of the cone seems always to be continuous with the metaxylem. Continuity of metaxylem and protoxylem is characteristic also of the internodes of the cone of E. debile and $E$. variegatum, though occasional indications of a local separation of protoxylem and metaxylem by one or two parenchymatous cells may be observed.

The above remarks may be summarized by saying that the separation or continuity of metaxylem and protoxylem depends chiefly on the relative radial extent of the former. Where the development of metaxylem is chiefly in a lateral direction (e.g. E. arvense and E. maximum) separation of metaxylem and protoxylem in the internodes is the result. Where, as in E.giganteum, the metaxylem (whether disposed in wide or narrow bundles) is of considerable depth it remains in contact with the protoxylem. Though the internodal strands in the cones of $E$. debile and $E$. variegatum are on a small scale, so that the actual number of tracheides present is small, the radial extent of the metaxylem is considerable compared with its width. The continuity of protoxylem and metaxylem in the internodes of the cones of these species is, therefore, not surprising. In the species in which the protoxylem may be either continuous with or separate from the metaxylem continuity usually occurs when rather more metaxylem is present radially or, more rarely, if the band of metaxylem is slightly incurved. If the vascular system of the cone is a reduced siphonostele it would seem to follow that the separation of protoxylem and metaxylem is a derivative character, resulting from poor development of the metaxylem radially. It should be pointed out that although it is possible that in some cases parenchymatous cells may have been destroyed during the formation of the carinal canals, yet this possibility does not allow of our regarding the metaxylem abutting on the canal as originally separate from the protoxylem; for in many cases the metaxylem at the edge of the canal is 
actually continuous with the partially disorganized tracheides projecting into the latter. Moreover, in some specimens of the species in question continuity of metaxylem and protoxylem may be observed before the destruction of the latter is completed.

'Although such species as $E$. arvense and $E$. maximum show a definite network of strands with short meshes, in E.palustre, E. limosum, E.sylvaticum, the meshes are more irregular-frequently much elongatedstretching for two or more "nodes", and in E. palustre even extending the whole length of the cone' (Barratt, p. 226).

As regards this second quotation I find myself unable to agree to the inclusion of E. maximum among the species, the stele of the cone of which shows a definite network of short meshes. An examination of Pls. XII and XIII of my paper dealing with the cone of this species will show that the stele possesses a very irregular network of meshes, many of which are long. This is true especially of the larger of the two cones, in which one of the meshes is of the seventh order, and twelve others are of the eighth or higher orders (Browne (2), Pls. XII and XIII). The only reconstruction of part of the network of the cone of E. maximum published by Barratt contains too few meshes to afford a reliable basis for generalization. Only thirteen meshes or portions of meshes of any considerable extent are shown; of these, however, only five are of the first order, while two are entering unclosed upon a fourth internode. Again, though in the cones of $E$. palustre the meshes are, on an average, much longer than those of $E$. arvense, they can hardly be said to extend nearly the whole length of the cone, at any rate on the evidence published, though of course this may be so in specimens with a reduced vascular system. ${ }^{1}$ Such a description would, however, apply to certain of the meshes of the cones of E. limosum.

After concluding that the existing structure in vegetative and reproductive axes has been derived from a siphonostele, Barratt proceeds to deal with the problem of the determining factor associated with the distribution of the parenchymatous tracts. Of this question she writes: 'Can it be met by an application of the conception of foliar gaps which is associated with the study of filicinean anatomy? Browne ${ }^{2}$ has attempted such an explanation in her papers dealing with the cones of several species of Equisetum. She homologizes the parenchymatous meshes with foliar gaps, associating them with sporangiophores, and considers that these organs are modified ${ }^{\oplus}$ whole foliar structures....

'Even if the sporangiophores were foliar structures, the anatomy does not favour the view that the meshes are foliar gaps. Jeffrey has pointed

1 In the case of the reconstruction published by me (Browne (1), Text-fig. 4) of the stele of the variety polystachion of $E$. palustre the meshes may be said to extend nearly the whole length of the cone. This is, however, not due to their height, but to the reduction of the whorls of these cones, borne on lateral branches, to four.

2 i. e. the present writer. 
out, and it is abundantly confirmed in this investigation, that the gap does not, except in a few cases, occur immediately above the point of departure of the trace ; and most frequently shows no relation to it.' (Barratt, p. 23I.)

Barratt's own view on the determining factor in the distribution of parenchymatous meshes is given as follows on p. 227 of her paper: 'It is suggested that the determining factor in the relative development of the metaxylem, and hence of the meshes, is primarily a mechanical one. It is significant that the species with large and heavy cones have more abundant xylem and more regularly developed network.'

The first point that I should like to emphasize in connexion with the above quotations is that I have never regarded the parenchymatous tracts of the cone as foliar gaps, or even as gaps left by the traces of the sporangiophores. In my first papei treating of the cone of Equisetum I especially pointed out that the parenchymatous meshes of the axis of the cone, like those of the vegetative axis, do not, except at the reduced or immature apex of the cone, originate immediately above the traces, and that they are not foliar gaps as defined by Jeffrey (Browne (1), p. 698). I proceeded to compare these meshes with the tracts of parenchyma that originate some way above the traces of certain Osmundaceae, and pointed out that these Osmundaceous parenchymatous tracts were not, when they originated some way above the trace, foliar gaps. I held that the structure now found in the axis of the cone of Equisetum was derived from a siphonostele, a view with which Barratt has expressed agreement. I further suggested that in the phylogeny the parenchymatous meshes probably arose in the internodal region vertically above traces-not a surprising position when we remember that the current of water, some of it being deflected into the sporangiophores, would be diminished above the departure of the traces. But I especially added that the cases in which the mesh arose closer to the trace were probably instances of the reduction of xylem (Browne (1), p. 699). In fact, it was to emphasize the point that the parenchymatous tracts of the cone were not foliar gaps that I distinguished them by the term mesh.

Barratt's statement that the meshes of the cone most frequently show no relation to the departure of the traces seems to me unjustified. An examination of the reconstructions of complete steles of the cones of E. arvense, E. palustre, E. limosum (Browne (1), Text-figs. I, 3, 5, and 6), E. maximum (Browne (2), Pls. XII and XIII), E. hyemale, E. giganteum (Browne (3), Text-figs. 2, 3, 4, 5, 6, and 7), E. sylvaticum and E. variegatum (Text-figs. I, 2, 8, 9, and Io of the present paper) will show that in by far the greater number of cases meshes originating within the cone do show a relation to the point of departure of a trace; for, in the great majority of cases, these meshes arise vertically above the departure of a trace of the node below, though at a varying height above this node. In E. debile (Text-figs. 3-7 of the present paper) few meshes originate within the cone 
itself. In Cones $\mathrm{A}, \mathrm{C}$, and $\mathrm{E}$ much of the parenchyma found in the steles consists of meshes that arose above the last whorl of leaves and persist well into the cone. In Cone $\mathrm{E}$, indeed, only two fresh meshes originate within the cone proper-i.e. definitely above the basal whorl of sporangiophores. ${ }^{1}$ But even in the cones of $E$. debile, where the vascular system is so reduced, never less and sometimes more than half the parenchymatous meshes originating within the cone itself arise vertically above traces of the node below. ${ }^{2}$ Taking into consideration the reconstructions of the steles in all the nine species studied, the proportion of meshes that arise vertically above traces is very large. Moreover, the fact that this relationship is much more prevalent in species with more metaxylem and shorter meshes is surely an argument in favour of the primitiveness of that position for those who, like Barratt and myself, look upon the primitive type of vascular structure in the cone as a siphonostele. Though it is suggested that the primitive form of mesh was probably one of the first order, originating at a point superposed to and some way above a trace of the whorl below, it is not, of course, claimed that in any one cone on the line of descent of Equisetum a parenchymatous mesh of the first order was found above every trace. Indeed, this was almost certainly not so, since some of the existing species of Equisetum retain in places wide internodal sweeps of xylem, apparently a vestige of the former siphonostele, although all the existing species of the genus possess some meshes of orders higher than the first.

The only argument given in support of the suggestion that the factor governing the distribution of the meshes of parenchyma may be a mechanical one is that 'the species with large and heavy cones have more abundant xylem and more regularly developed network' (Barratt, p. 227). It has already been pointed out that in the cones of E. maximum, the largest of the genus, there is a very irregularly developed network and relatively little xylem. Of course, in a cone of this species which, like Cone A of my paper on E. maximum, consists of over six hundred sporangiophores there are actually a large number of tracheides, although the xylem is poorly developed relatively to the parenchyma. ${ }^{3}$ I have previously suggested that while the length of the cones seems to have little effect on the height of the meshes the width of the stele has a bearing on the closure or persistence of the meshes through the node. I wrote: 'But if the reduction in width of the stele did not keep pace with the reduction of the xylem at the

1 In estimating the nature and incidence of the parenchymatous meshes of this cone and of Cone $\mathrm{B}$ of the same species it must be remembered that the broken line enclosing a dotted surface marks the extent to which the differentiation of metaxylem would presumably have attained had the cone been mature.

2 An indirect confirmation of the view that the cones of this species are amongst the most reduced of those studied is afforded by the fact that in the branches bearing them the ring of xylem at the last node may be incomplete, a condition not hitherto recorded for other normal nodes.

3 This cone was not exceptionally large. It was about three inches long, and I have seen cones fully four and a half inches in length. 


\section{Broune.-A Fourth Contribution to our Knowledge of}

neighbourhood of the node, the direct and immediate effect would be for some of the meshes to persist into the internode above. I think that this is the explanation of the greater reduction of the vascular system in the cones of the species of Equisetum that have relatively wide steles.' I then pointed out that of the four species so far studied the two with the widest steles, $E$. maximum and $E$. limosum, had the most reduced vascular system, while within the limits of the single species, where the examples studied had steles showing a marked difference in diameter, the more irregular and reduced vascular network was always found in the specimens with wider steles. I added: 'Of course the width of the stele is not the only, nor the principal factor causing reduction of the vascular system ; it is, for instance, characteristic of $E$. arvense to have cones containing more axial xylem, both actually and relatively to their size, than those of E.palustre, though the steles of the former species are usually much wider than those of the latter' (Browne (2), pp. 259-60).

The generalization contained in the former quotation should, I think, be modified by the intercalation after the words 'at the neighbourhood of the node' of the following passage: 'or with the reduction in number of the members of the whorls.' This qualification is necessary to cover cases, like that of $E$. debile, in which the whorls of the cone consist of few members, so that though the diameter of the stele is actually small the narrow internodal strands are separated by relatively wide parenchymatous meshes. We naturally find that in the species in which the meshes are wide compared with the internodal strands (E. maximum, E. limosum, E. variegatum, and $E$. debile) they are less regularly closed than in the species with narrow meshes relatively to the strands ( $E$. arvense and $E$. palustre), since the junction of a strand with its neighbour or neighbours can here be effected by the differentiation of comparatively little xylem additional to that present in the internode. E. sylvaticum and E. giganteum occupy a middle position between the types with relatively wide and relatively narrow meshes. E. hyemale, with its wide stele and narrow internodal strands separated by wide tracts of parenchyma, is an exception to this generalization; for it shows a large number of meshes, many of them of the first or low orders. In the cone of this species the difficulty of anastomosis between widely separated narrow strands has been, to a large extent, met by the oblique course of the tracheides on each side of the base of the meshes. Speaking phylogenetically, we should say that in spite of the reduction of the xylem the connexion of the nodes of the vascular strands has been in many cases maintained by the oblique course of the halves of the forking strands. The divergence of these branches of strands frequently results in their fusion with the neighbouring fork of a strand (as in the vegetative axis of Equisetum generally), or, if the neighbouring strand be unforked, with the latter itself. In either case this causes the closure of a mesh slightly above the level of departure of the trace. 
That the course of the protoxylem should be irregular is only what we should expect to find in a stele undergoing reduction. In so far as the elements of the protoxylem are the first tracheides to be differentiated in the ontogenetic building up of the stele I think that the protoxylem system may well be compared, as it is by Barratt, to a scaffolding. She, however, also states that the whole vascular system of the cone is built up on this scaffolding, and claims that the protoxylem strands determine the main features of the vascular system (Barratt, pp. 222 and 225). If it were so the comparison would be an unfortunate one, for a building is constructed by means of a scaffolding, but not on a scaffolding, a temporary structure that disappears. I do not, of course, mean that the protoxylem is merely a temporary scaffolding, for it remains functional though some of its elements are destroyed, and undoubtedly plays an important part, since it constitutes the first and by 'far the principal source of the vascular supply of the sporangiophores. But that the protoxylem strands should alone determine the main features of the vascular supply is hardly tenable ; for the development of a parenchymatous mesh above a trace, though occurring later in the octogeny, must be associated with the forking or swerving or the dying out of the strand of protoxylem, unless the trace is one of those borne on a short lateral stalk of protoxylem (see below and p. 454). Both the dying out of protoxylem below a mesh and its swerving to one side of the latter seem to be derivative conditions, associated with less vigorous development of the protoxylem. In the reconstructions of the steles of Cone B of E. sylvaticum (Text-fig. 2) and of Cone A of E. debile (Textfig. 4) the course of the protoxylem is indicated by a broken white line. Where the growth in thickness has caused the destruction of the protoxylem and its replacement by a lacuna the width of the latter is shown by a dotted surface. The original elements did not, of course, occupy so wide a space as the lacuna. It will be seen that, especially in E. sylvaticum, in which the vascular system is better developed, forking of the protoxylem occurs in many cases below a mesh. When the protoxylem forks such forking obviously occurs before the appearance of a mesh causes the division of the metaxylem, and it not infrequently takes place a little below the departure of the trace. This is by no means surprising, as when a stele or meristele is about to fork the division of its protoxylem often occurs somewhat prematurely. When the division of the protoxylem occurs thus early the trace often appears as though terminating a short median prolongation of the protoxylem between the two forks of the latter. In the case of some of the protoxylem strands that pass unforked through the node the trace also appears in the reconstructions to be seated on a short stalk, though in this case on a lateral one. In such cases the protoxylem of the appendage departs from that of the axis a little below the exit of the trace from the stele, and, as the sporangiophore to which the trace is destined does not 


\section{Browne.-A Fourth Contribution to our Knowledge of}

lie opposite the axial strand, the vascular supply as it passes gradually upwards and outwards through the bundle curves towards the sporangiophore and comes to lie on a different radius from the parent strand of the axis. Thus it is shown as a separate broken line in the reconstruction. The cases in which the axial protoxylem is shown in the diagrams as passing straight and uninterruptedly upwards above the traces are of three sorts. Firstly, the protoxylem of the trace may pass out horizontally, and then the axial protoxylem does not branch below the trace; or the protoxylem of the latter may enter a sporangiophore on the same radius as the axial strand, and so never became apparent as a separate branch in the reconstruction; or, lastly, such a trace may enter a sporangiophore to one side of the axial protoxylem, but the curvature of the trace may occur in the cortex (cf. Browne (2), p. 26I, on the twisting of the traces in the cortex of E. maximum).

That the course of the protoxylem as well as the distribution of the metaxylem has been affected by reduction seems to me confirmed by the fact that in Cone B of E. sylvaticum the protoxylem entering the ninth sporangiophore of the eighth whorl, and that of the fourth sporangiophore of the uppermost whorl, are not continuous with the rest of the protoxylem of the cone. The protoxylem of the axial strand giving rise to the ninth trace of the eighth whorl forms a particularly distinct canal, abutting at its lower end on very definite metaxylem tracheides. This means that in the ontogeny the cells just below the lower end of the axial protoxylem had reached a considerable size before they were differentiated as tracheides, and that such differentiation occurred later than the differentiation of the tracheides of the protoxylem immediately above them.

We may perhaps recognize in the incomplete fusion of certain protoxylems, which is one of the irregularities of the protoxylem 'system', a phenomenon associated with prematurely divided traces. Such approximation of protoxylems, not leading to their junction, as is found, for example, at the point of departure of the eighth trace of the fourth whorl of Cone B of E. sylvaticum, causes the trace to originate as separate halves. This failure of two protoxylems to fuse into a single one is, it may be noted, associated with a failure of one of the strands to branch at the node below, and the persistence of the mesh through this lower node to a point just below. the next node. In this case the metaxylem of the two strands, which fuses just before the fourth node, clearly reproduces the more primitive condition, lost by the protoxylem.

\section{' Summary.}

I. The vascular system of the cone of E. sylvaticum resembles on a smaller scale that of the cone of E. maximum; relatively to its size: it is better developed. 
2. The vascular system of the cone of $E$. debile is much reduced and forms a loose irregular network. Frequently numerous parenchymatous meshes originating below the cone persist for a considerable distance into the cone, some of them even traversing the whole cone.

3. The stele of the cone of E.variegatum is also of a somewhat reduced type.

4. On grounds of comparative anatomy the separation of protoxylem and metaxylem in the internodes of the cones of certain species of Equisetum, a condition most marked in $E$. maximum, is regarded as a derivative character, due chiefly to reduction of the radial extent of the metaxylem.

5. It is concluded that a comparative study confirms the view already put forward that parenchymatous meshes of the cone probably first arose, in the phylogeny, at points vertically above the departure of the traces of sporangiophores, though at a certain height above this level. They were, therefore, not true gaps, as defined by Jeffrey. In the cases in which the meshes arise very close above the departure of the trace, this approximation is probably due to reduction of xylem during the phylogeny. The primitive system was probably siphonostelic.

6. The following points in the anatomy of $E$. sylvaticum support the view that the insertion of the annulus marks the position of a vestigial node: (a) the numerous anastomoses of the axial strands at this level; (b) indications of anastomosis of the protoxylem at the same level ; $(c)$ the presence in the axis opposite the annulus of Cone $\mathrm{B}$ of an abortive trace that never becomes free; $(d)$ the presence in this same cone at the level of insertion of the annulus of tracheides somewhat resembling those of the nodal xylem of the vegetative axis; (e) the occurrence, according to Milde, of branches below the annulus.

7. In one of the cones of E. debile four small groups of vascular cells were observed in the parenchyma of the annulus. Though they are unconnected with cells of the axial bundle it is possible that these vascular cells represent vestiges of the traces of the annular node. In this species, however, and still more in E. variegatum, there are but few indications of the former presence of a node at the insertion of the annulus.

8. In some specimens of $E$. debile the ring of nodal or (supranodal) xylem is not complete at the level of the uppermost whorl of leaves.

My thanks are due to Professor F. W. Oliver, F.R.S., in whose laboratory the present investigations were carried out, not only for his continued help and encouragement, but also for material of $E$. variegatum. Major T. G. Hill, A.R.C.S., most kindly gave me the benefit of his advice on certain points of technique. I also wish to thank Dr. Shriv Yam Kashyap, who sent me from India a most generous supply of the cones of E. debile, of all sizes and ages; and Miss Agnes Fry, who supplied me with cones of E. sylvaticum. 


\section{LITERATURE CITED.}

Barratt, K. : A Contribution to our Knowledge of the Vascular System of the Genus Equisetum. Annals of Botany, vol. xxxiv, 1920.

Browne, I.: (1) Contributions to our Knowledge of the Anatomy of the Cone and Fertile Stem of Equisetum. Ibid., vol. xxvi, I9I 2.

: (2) A Second Contribution to our Knowledge of the Anatomy of the Cone and Fertile Stem of Equisetum. Ibid., vol. xxix, I915.

: (3) A Third Contribution to our Knowledge of the Anatomy of the Cone and Fertile Stem of Equisetum. Ibid., vol. xxxiv, 1920.

Chodat, R.: Les Ptéropsides des temps paléozoïques. Archives des Sciences physiques et naturelles, vol. xxvi, pp. I-44, I908.

Duval-Jouve, J. : Histoire naturelle des Equisetum de France. Paris, I864.

Janczewski, E. DE : Recherches sur le développement des bourgeons dans les Prêles. Mémoires de la Société nationale des Sciences naturelles de Cherbourg, vol. $\mathrm{xx}, \mathrm{I} 876$.

Milde, J. : Monographia Equisetorum. Nova Acta Academiae Caesareae Leopold. Caroli Germanici Naturae curiosorum, vol. xxiv, 1867 .

Pfitzer, E. : Über die Schutzscheide der deutschen Equisetaceen. Pringsheim's Jahrbücher für wissenschaftliche Botanik, vol. vi, i 867-8.

\section{EXPLANATION OF PLATE XXI.}

Illustrating Lady Isabel Browne's paper on the Anatomy of the Cone and Stem of Equisetum.

Fig. I. Transverse section of part of the axis of Cone B of E. sylvaticum a little above the insertion of the annulus. Note relatively numerous tracheides, some rather wide. $\quad \times 65$.

Fig. a. Transverse section of part of the axis of Cone B, taken a little below Fig. I, but still slightly above the insertion of the annulus. Note the forking of some of the protoxylem canals; other bundles still retain a single, relatively large carinal canal, such as characterizes all the bundles in the lower part of the internode. $\times 65$.

Fig. 3. Transverse section through part of the axis and annulus of Cone $\mathrm{E}$ of E. debile, showing a longitudinal view of one of the tracheides of a small free annular bundle. The photograph is taken at the level at which the annular vascular tissue approaches closest to the axial stele. $\times 250$.

Fig. 4. Transverse section of the stele of the cone of E. variegatum near the level of a node. As the sporangiophores are not inserted absolutely at the same level the section only passes through the insertion of two of the traces. $\times$ I 25.

Fig. 5. Transverse internodal section of the stele of E. variegatum. One of the bundles on the reader's left shows the relatively large deeply seated tracheides of the metaxylem particularly clearly. $\times \mathrm{I} 25$.

FIG. 6. Transverse section of the axis of $E$. debile between the last whorl of leaves and the insertion of the annulus. Note that the bundles are situated opposite the grooves of the stem. $\times 3^{\circ}$.

Fig. 7. Transverse section of part of the stele of an internode of the cone of E. debile. Note the difference in the size of the bundles and the different degree of destruction of the protoxylem. Other points to be noted are the definite sheaths surrounding the bundles, the wide parenchymatons meshes, and the relatively large size of some of the deeper seated metaxylem tracheides. $\times 6_{5}$.

Fig. 8. Transverse section through a node of the stele of $E$. variegatum. This specimen was exceptionally large and the xylem unusually well developed. $\times$ I25.

Fig. 9. Upper surface of the annulus of Cone B of $E$. debile, showing two stomata. $\times 500$. 
Annals of Botany,

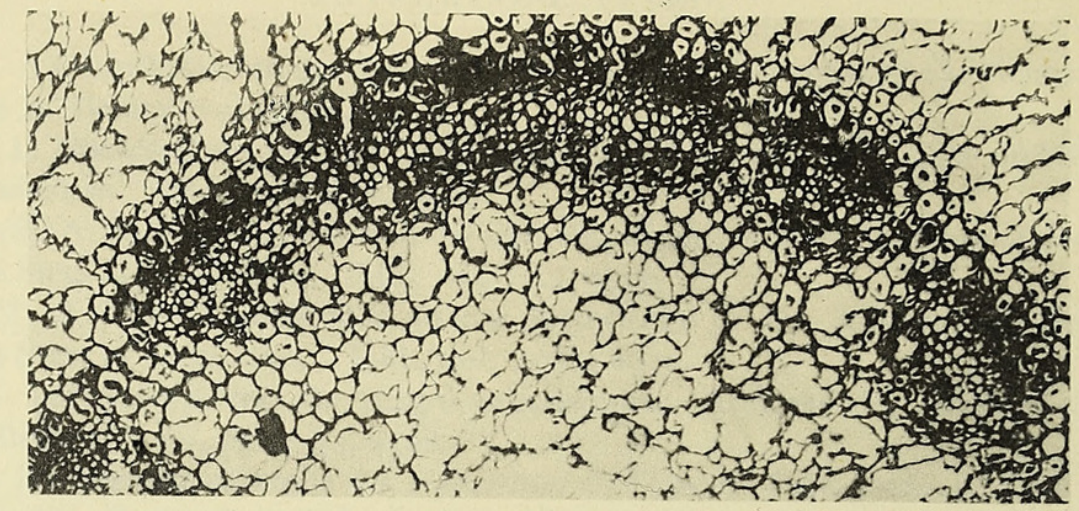

1 .
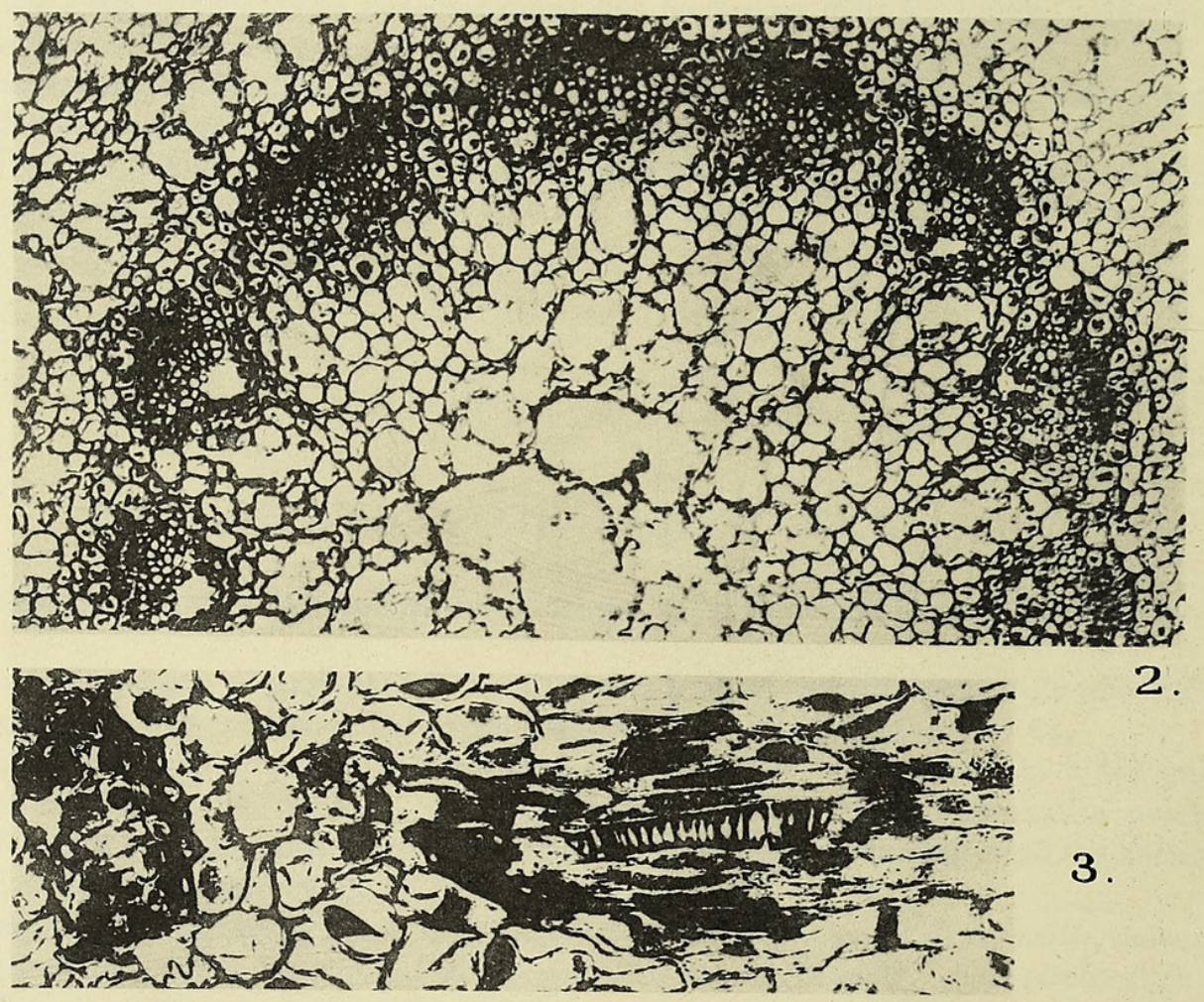

2.

3.

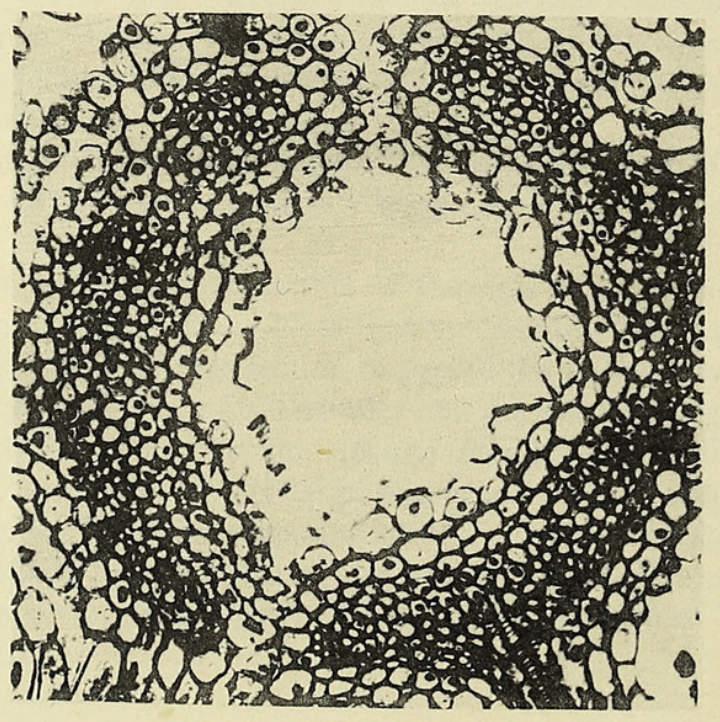

4.

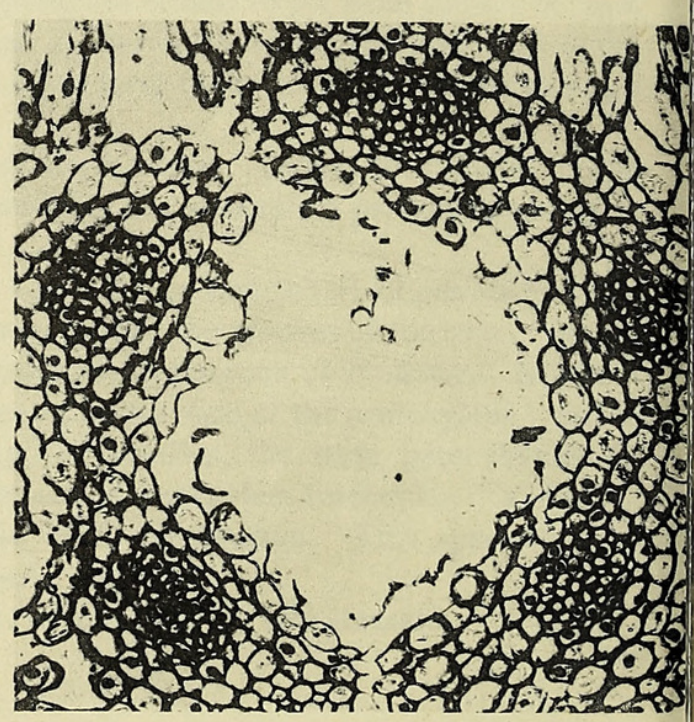

5.

1. M. P. BROWNE-EQUISETUM. 


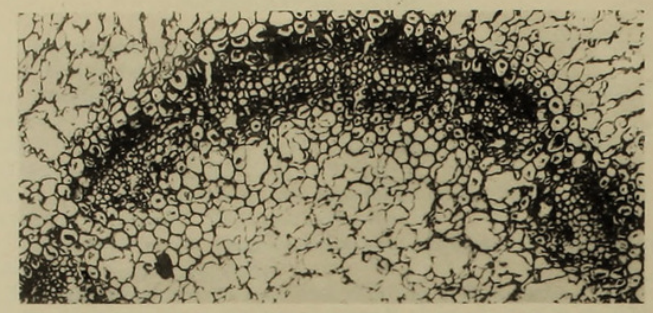
(1)

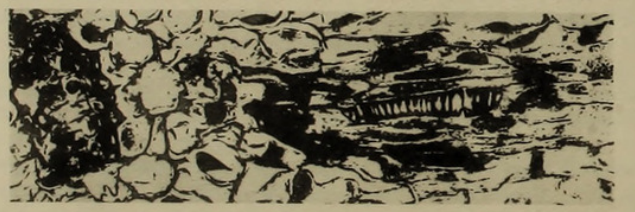

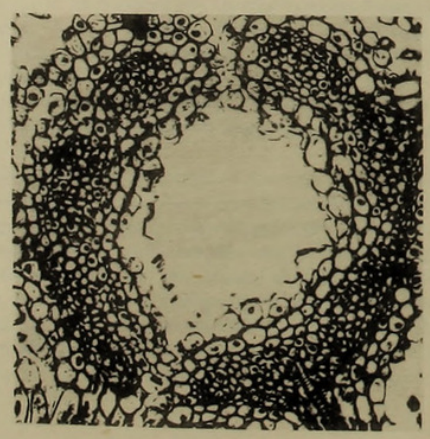

4.

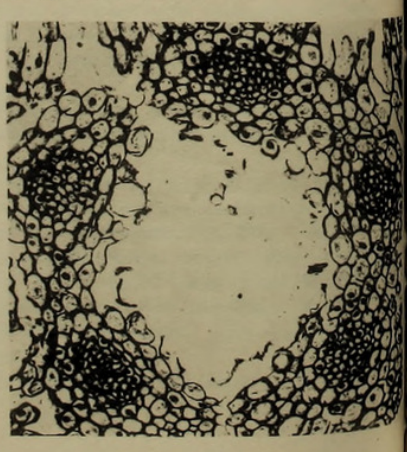

5.
I. M.P. BROWNE-EQUISETUM.
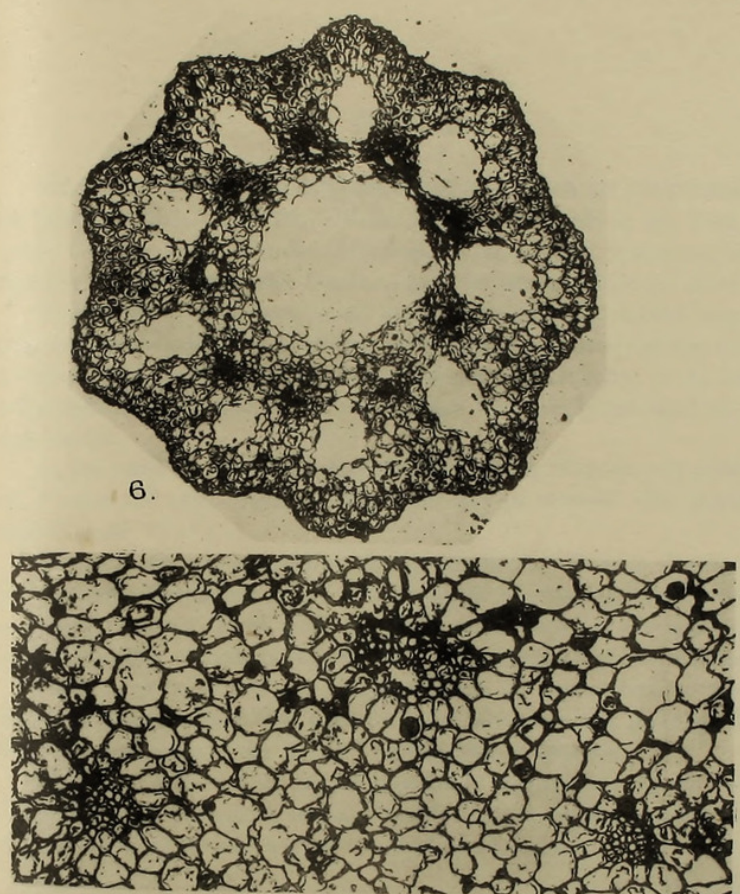

3. $5200000 \%$

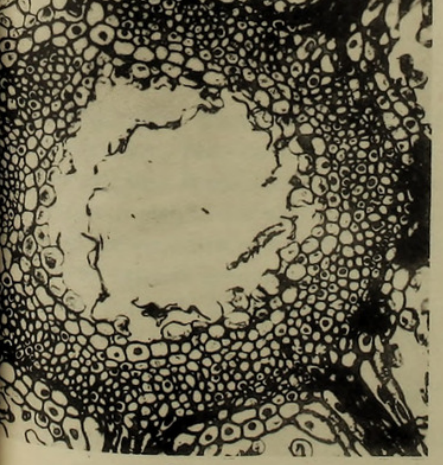

8.

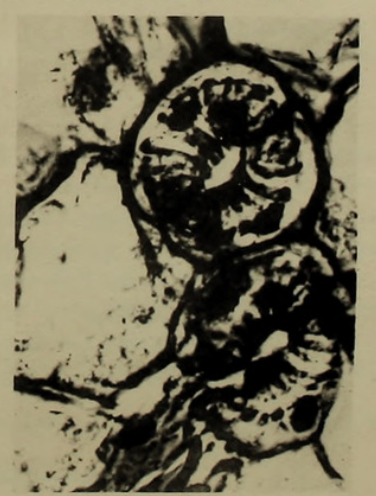

9 . 


\section{E R R A T U M}

Annals of Botany, Vol. XXXV, No. CXXXIX, July, I92 I

Page 449, line I6 for seventh read seventeenth 


\section{$2 \mathrm{BHL}$ Biodiversity Heritage Library}

Browne, Isabel. 1921. "A fourth contribution to our knowledge of the anatomy of the cone and fertile stem of Equisetum." Annals of botany 35, 427-456. https://doi.org/10.1093/oxfordjournals.aob.a089766.

View This Item Online: https://www.biodiversitylibrary.org/item/235780

DOI: https://doi.org/10.1093/oxfordjournals.aob.a089766

Permalink: https://www.biodiversitylibrary.org/partpdf/319011

\section{Holding Institution}

Smithsonian Libraries

\section{Sponsored by}

Biodiversity Heritage Library

\section{Copyright \& Reuse}

Copyright Status: Not in copyright. The BHL knows of no copyright restrictions on this item.

This document was created from content at the Biodiversity Heritage Library, the world's largest open access digital library for biodiversity literature and archives. Visit BHL at https://www.biodiversitylibrary.org. 